Check for updates

Cite this: J. Mater. Chem. A, 2021, 9, 20436

Received 22nd June 2021

Accepted 3rd August 2021

DOI: $10.1039 / d 1 t a 05289 f$

rsc.li/materials-a

\section{Applications of thermodynamic calculations to practical TEG design: $\mathrm{Mg}_{2}\left(\mathrm{Si}_{0.3} \mathrm{Sn}_{0.7}\right) / \mathrm{Cu}$ interconnections $\uparrow$}

\author{
Silvana Tumminello, (D) *a Sahar Ayachi, ${ }^{a}$ Suzana G. Fries, ${ }^{b}$ Eckhard Müller ${ }^{\text {ac }}$ \\ and Johannes de Boor (D) ad
}

Magnesium silicide stannide solid solutions, $\mathrm{Mg}_{2}(\mathrm{Si}, \mathrm{Sn})$, are prominent materials in the development of devices for thermoelectric energy conversion for intermediate operating temperatures, owing to the high values of their thermoelectric figure of merit $z T$, elemental abundance, and non-toxicity. The manufacturing of thermoelectric generators, however, relies also upon long-term stable contacts with low thermal and electrical resistivity and good bonding of the metallic contact bridge (electrode) to the thermoelectric legs of $\mathrm{Mg}_{2}(\mathrm{Si}, \mathrm{Sn})$ with a similar thermal expansion coefficient. In the assembly of thermoelectric generators, the thermoelectric legs have to be bonded to metallic electrodes to establish an electrical circuit. In this work, contacts between $\mathrm{Mg}_{2}\left(\mathrm{Si}_{0.3} \mathrm{Sn}_{0.7}\right)$ and $\mathrm{Cu}$ were made at $600{ }^{\circ} \mathrm{C}$ and investigated using thermodynamic equilibrium calculations to gain understanding on the phase transformations occurring in the bonding process. $\mathrm{Cu}$ is selected as a metallic electrode as it is a highly conductive element with a thermal expansion coefficient similar to that of the thermoelectric material. Contacting methods usually deviate from equilibrium conditions; nevertheless, we use this contact couple to illustrate that equilibrium thermodynamic considerations are an efficient support to anticipate and identify the reaction products forming the final microstructure of the bonded region, and ultimately, for improving the contact design. A thermodynamic database of Gibbs energies for quaternary $\mathrm{Cu}-\mathrm{Mg}-$ $\mathrm{Si}-\mathrm{Sn}$ was built up and made available in this work. With this database, thermodynamic calculations were done in order to complement the experimental observations on the microstructure and thermochemistry of the $\mathrm{Mg}_{2}\left(\mathrm{Si}_{0.3} \mathrm{Sn}_{0.7}\right) / \mathrm{Cu}$ interconnections. The approach developed in this work is general and therefore applicable to the investigations of different thermoelectric materials and/or metallic electrodes, by enlarging the thermodynamic description, providing an effective guide to the experimental settings of the contacting process.

\section{Introduction}

Thermoelectric devices for power generation (thermoelectric generators, TEGs) convert heat into electricity through the Seebeck effect. Practical TEGs require a tailored design and engineering of the thermoelectric (TE) material, stable contacting with the metallic bridges (electrodes) and durable

Institute of Materials Research, German Aerospace Center, D-51170 Cologne, Germany. E-mail: silvana.tumminello@dlr.de

${ }^{b}$ Materials Research Department, Ruhr University Bochum, D-44801 Bochum, Germany 'Institute of Inorganic and Analytical Chemistry, Justus Liebig University Gießen, D35392 Gießen, Germany

${ }^{d}$ Institute of Technology for Nanostructures, University of Duisburg-Essen, D-47057 Duisburg, Germany

$\dagger$ Electronic supplementary information (ESI) available: Cu-Mg-Si-sn_thermodynamic_description.TDB: is the thermodynamic database for the quaternary system $\mathrm{Cu}-\mathrm{Mg}-\mathrm{Si}-\mathrm{Sn}$; cumgsisn_supplement_info.pdf: includes the calculated isotherm for $\mathrm{Mg}-\mathrm{Si}-\mathrm{Sn}$ at $700{ }^{\circ} \mathrm{C}$. See DOI: $10.1039 / \mathrm{d} 1 \mathrm{ta} 05289 \mathrm{f}$ assembly technology for applicable modules., ${ }^{1,2}$ Magnesium silicide stannide solid solutions arise as prominent TE materials, owing to the high values of their thermoelectric figure of merit $z T$, elemental abundance, and non-toxicity. Recently the improved TE properties of p-type $\mathrm{Mg}_{2}\left(\mathrm{Si}_{1-x} \mathrm{Sn}_{x}\right)$ materials ${ }^{3-5}$ allow the use of the same base material for both p- and n-type TE legs, ${ }^{6-9}$ reducing the thermomechanical complexity of the modules and simplifying the selection of electrodes for practical devices. The operation of a TEG also relies upon long-term stable contacts with low thermal and electrical resistivity, similar thermal expansion coefficients of the bonding parts and good bonding of the conducting electrode to $\mathrm{Mg}_{2}\left(\mathrm{Si}_{1-x} \mathrm{Sn}_{x}\right)$ for intermediate operating temperatures $\left(300-500{ }^{\circ} \mathrm{C}\right)$. A cross section of a conventional TEG is shown in Fig. 1, with two n-/pleg pairs and $\mathrm{Cu}$ as the electrode working in a temperature gradient (hot/cold side). The zoom-in image shows the region of interest for the contacting process, $\approx 300 \mu \mathrm{m}$ near the initial $\mathrm{Mg}_{2}\left(\mathrm{Si}_{0.3} \mathrm{Sn}_{0.7}\right) / \mathrm{Cu}$ interface. 


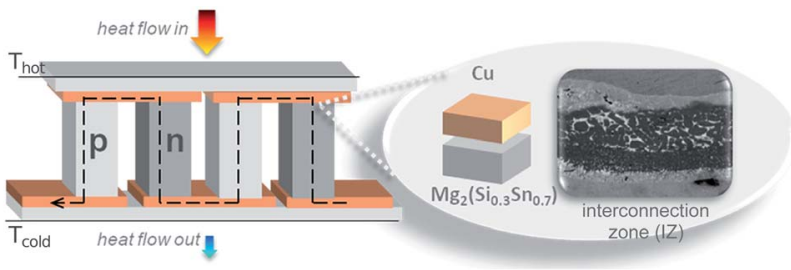

Fig. 1 Scheme of the cross section of a TEG showing two $n-/ p$-leg pairs in a temperature gradient (hot/cold side) and dashed line indicating electrical current. Zoom-in image of the region of interest for the contacting process close to the original $\mathrm{Mg}_{2}\left(\mathrm{Si}_{0.3} \mathrm{Sn}_{0.7}\right) / \mathrm{Cu}$ interface.

Experimental investigations on $\mathrm{Mg}_{2}\left(\mathrm{Si}_{0.3} \mathrm{Sn}_{0.7}\right) / \mathrm{Cu}$ junctions ${ }^{10}$ showed low specific electrical contact resistances $(<10$ $\mu \Omega \mathrm{cm}^{2}$ ), good bonding and no delamination. In the same work, $\mathrm{Cu}$ was indicated as a potential candidate electrode for $\mathrm{n}$ - and $\mathrm{p}$ type TE legs though its influence on the functionality of the TE material is still under investigation. Accordingly, further insights are given in this work with special attention on phase transformations and diffusion-reaction phenomena occurring in the vicinity of the semiconductor/metal interface, namely the interconnection zone (IZ). We combine equilibrium calculations with chemical SEM/EDX analysis to understand the observed microstructure of $\mathrm{Mg}_{2}\left(\mathrm{Si}_{0.3} \mathrm{Sn}_{0.7}\right) / \mathrm{Cu}$ contacts and its further relationship with the bonding stability. The synthesis of TE legs and the leg/electrode contact entail several stages such as melting, mechanical milling and sintering, which are typically non-equilibrium processes; nevertheless, we show the effectiveness of equilibrium thermodynamics in providing understanding on phase stability and metastability throughout the technological processing of TEGs.

An overview of the application of thermodynamic calculations of phase diagrams to TE material design has been recently published; ${ }^{\mathbf{1 1}}$ herein we broaden with this work the applications of thermodynamic modeling and calculations to the investigation of TE material/metal interconnections. We present the results for a $\mathrm{Cu}$ single element electrode as a case study, where the use of equilibrium thermodynamics provides ample information. Even when diffusion calculations are needed this approach can be used by coupling thermodynamic and diffusivity descriptions. ${ }^{12}$ Additionally, its extension to multicomponent electrodes is done by including each element in the thermodynamic description as described hereunder for this quaternary. This represents an advantage to handle electrodes with higher chemical complexity such as $\mathrm{Mg}_{2} \mathrm{SiNi}_{3}$ and stainless steel $304,{ }^{\mathbf{1 3}, 14}$ and typically applied coatings like BN. The aim of this work is to establish an approach based on thermodynamics to investigate contacts, gain understanding and to show how this route can be improved. To this end, we take a $\mathrm{Mg}_{2}\left(\mathrm{Si}_{0.3^{-}}\right.$ $\left.\mathrm{Sn}_{0.7}\right) / \mathrm{Cu}$ contacting couple and a two step contacting process as a case study to illustrate the potential of our thermodynamic calculation aided approach. In the case presented here, aid was provided a posteriori, and in further work this approach will be used simultaneously with the design.

For the investigation of the mentioned contacts, a quaternary thermodynamic description for the $\mathrm{Cu}-\mathrm{Mg}-\mathrm{Si}-\mathrm{Sn}$ system is required. To the best of our knowledge, no such description is available in the literature; therefore, an open set of Gibbs energies was developed bringing together assessed binaries and ternaries from the literature and adapting the models for consistency in order to have a quaternary thermodynamic description. Of particular interest is the modelling of the quaternary extension of the C15 Laves phase and ternary $\tau_{1^{-}}$ $\mathrm{Cu}_{3} \mathrm{Mg}_{2} \mathrm{Si}$, previously designated as $\gamma-\mathrm{Cu}_{51.7} \mathrm{Mg}_{33.3} \mathrm{Sn}_{15}$ and $\tau_{1^{-}}$ $\mathrm{Cu}_{3} \mathrm{Mg}_{2} \mathrm{Si},{ }^{10}$ respectively, as they were observed to grow in the IZ. Their model is included in the assembled thermodynamic database (stored in a file called TDB).

The structure of the paper is as follows: in Section 2, we present the literature review for the known ternaries and binaries and we describe the thermodynamic models of the relevant phases, while the complete set of Gibbs energies (TDB file) can be found in the $\mathrm{ESI}^{\dagger}$ and the thermodynamic formalism in Appendix A. The experimental details are given in Section 3. Subsequently, in the Results and discussion Section 4, we describe the buildup of the quaternary database, Section 4.1, and the application of the thermodynamic calculations, Section 4.2. Finally, we conclude in Section 5.

\section{Thermodynamic modelling: literature review}

The knowledge of the Gibbs energies for all the phases in a material system allows the calculation of thermodynamic properties of multiphase materials and equilibrium between phases. This procedure is used in the well-established Calphad method $^{\mathbf{1 5}}$ to obtain calculated phase diagrams and thermodynamic properties; within this framework, a set of Gibbs energies was assembled in this work using thermodynamic parameters available in the literature. Thermodynamic parameters are determined using large amounts of experimental data, made available within the past 100 years; therefore, it is of common practice to select suitable binary descriptions, which reproduce the more complete set of experimental data available at the time, to build up higher order system descriptions. This hierarchy is of utmost importance allowing extrapolations to multicomponent systems based on well evaluated binary and ternary subsystems. ${ }^{16}$ In a quaternary system such as $\mathrm{Cu}-\mathrm{Mg}-$ $\mathrm{Si}-\mathrm{Sn}$, there are ten subsystems that need a thermodynamic description to get the quaternary information: four ternaries: $\mathrm{Mg}-\mathrm{Si}-\mathrm{Sn}, \mathrm{Cu}-\mathrm{Mg}-\mathrm{Si}, \mathrm{Cu}-\mathrm{Mg}-\mathrm{Sn}$ and $\mathrm{Cu}-\mathrm{Si}-\mathrm{Sn}$; six binaries: $\mathrm{Mg}-\mathrm{Si}, \mathrm{Mg}-\mathrm{Sn}, \mathrm{Si}-\mathrm{Sn}, \mathrm{Cu}-\mathrm{Mg}, \mathrm{Cu}-\mathrm{Si}$ and $\mathrm{Cu}-\mathrm{Sn}$. These constitutive systems are described hereunder calculating, for all the cases, isothermal sections at $600{ }^{\circ} \mathrm{C}$ due to the experimental contacting temperature.

\subsection{The Mg-Si-Sn system}

The ternary $\mathrm{Mg}-\mathrm{Si}-\mathrm{Sn}$ follows the thermodynamic description proposed by Kozlov et al. ${ }^{17}$ while the binaries were accepted from the respective references: $\mathrm{Mg}-\mathrm{Si},{ }^{18} \mathrm{Mg}-\mathrm{Sn}^{19}$ and $\mathrm{Si}-\mathrm{Sn},{ }^{20}$ and the calculated diagrams using the assembled TDB are shown in Fig. 2a. The compounds $\mathrm{Mg}_{2} \mathrm{Sn}$ and $\mathrm{Mg}_{2} \mathrm{Si}$ are known as semiconducting phases having the same stoichiometry and 

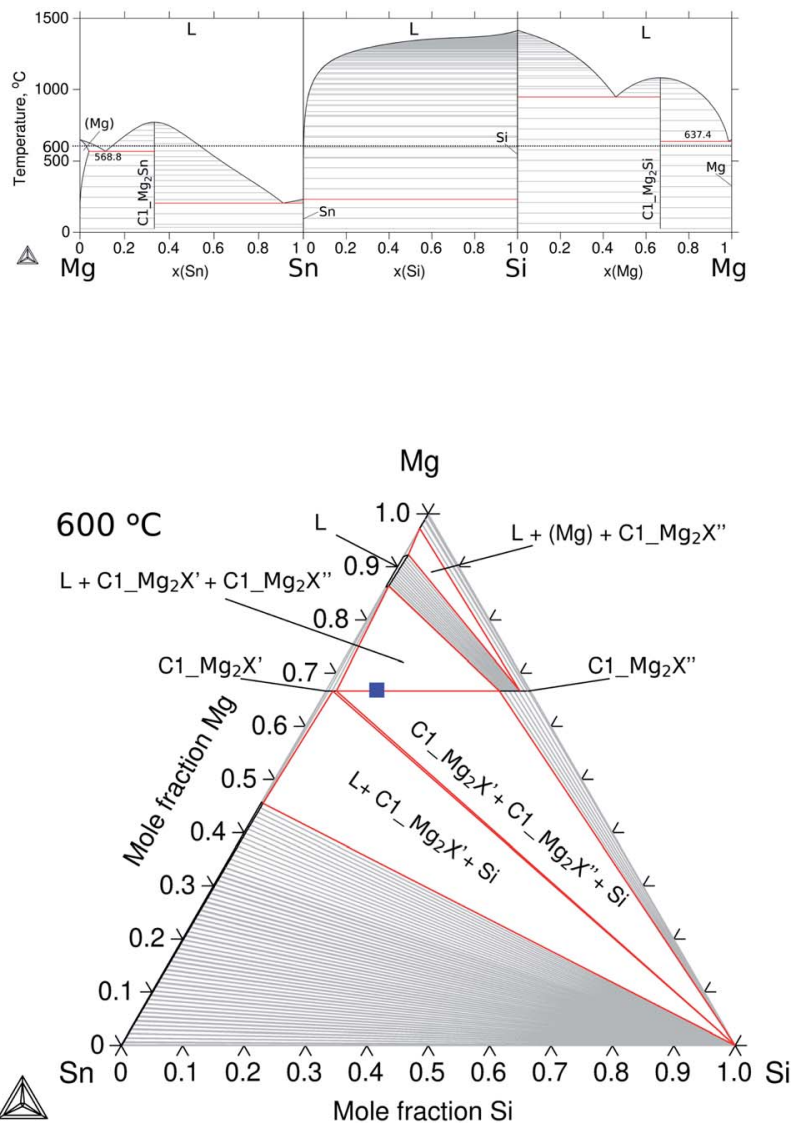

Fig. 2 Calculated equilibrium diagrams for the $\mathrm{Mg}-\mathrm{Si}-\mathrm{Sn}$ system using Thermo-Calc software $2021 a^{27}$ and the assembled thermodynamic database for this work with ternary parameters adapted from Kozlov et al. ${ }^{17}$ (a) Binary phase diagrams, $\mathrm{Mg}-\mathrm{Sn},{ }^{26} \mathrm{Sn}-\mathrm{Si}^{20}$ and $\mathrm{Si}-\mathrm{Mg} .{ }^{18}$ (b) Isothermal section at $600{ }^{\circ} \mathrm{C}$ of ternary $\mathrm{Mg}-\mathrm{Si}-\mathrm{Sn}$ and composition of the TE material, $\mathrm{Mg}_{2} \mathrm{Si}_{0.3} \mathrm{Sn}_{0.7}$, before contacting indicated with the blue square symbol.

crystal structure, cubic antifluorite with $\mathrm{Mg}$ occupying $8 a$ and $\mathrm{Si} / \mathrm{Sn}$ in $4 a$ Wyckoff positions (WPs), and space group $F m \overline{3} m$ type C1. They were labelled in this work using the Strukturbericht designation $\mathrm{C} 1 \mathrm{Mg}_{2} \mathrm{Sn}$ and $\mathrm{C} 1 \mathrm{Mg}_{2} \mathrm{Si}$. Due to their crystallography, they can form a solid solution in the $66.7 \mathrm{at} \% \mathrm{Mg}$ isopleth of ternary $\mathrm{Mg}-\mathrm{Si}-\mathrm{Sn}$; however, a wide miscibility gap in the solid phase with controversial solubility limits has been reported in phase equilibria determinations, ${ }^{17,21-23}$ and in phase investigations for thermoelectric applications. ${ }^{24,25}$

This particular isopleth represents the section $\mathrm{Mg}_{2} \mathrm{Sn}-\mathrm{Mg}_{2} \mathrm{Si}$ with two stable phases: the liquid and the solid $\mathrm{Mg}_{2} \mathrm{Si}_{1-x} \mathrm{Sn}_{x}$ labelled $\mathrm{C}_{-} \mathrm{Mg}_{2} \mathrm{X}$, where $\mathrm{X}=\mathrm{Si}$, Sn are known to share the same Wyckoff sites. The miscibility gap reported in the solid phase represents the mixture of two conjugated phases or compositions of maximal solubility, and it can be observed in the isothermal section at $600{ }^{\circ} \mathrm{C}$ in Fig. $2 \mathrm{~b}$, and a solid red line represents the equilibrium between the conjugated phases $\mathrm{C} 1 \_\mathrm{Mg}_{2} \mathrm{X}^{\prime}$ (maximum solubility of $\mathrm{Si}$ in $\mathrm{Mg}_{2} \mathrm{Sn}$ ) and $\mathrm{C} 1 \mathrm{Mg}_{2} \mathrm{X}^{\prime \prime}$ (maximum solubility of $\mathrm{Sn}$ in $\mathrm{Mg}_{2} \mathrm{Si}$ ). Within the miscibility gap, conjugated solutions can be simultaneously stable and are defined as composition sets in the thermodynamic calculations, i.e. $\mathrm{C} 1 \_\mathrm{Mg}_{2} \mathrm{X}^{\prime}$ is composition set $1(\mathrm{C} 1 \# 1)$ and $\mathrm{C} 1 \_\mathrm{Mg}_{2} \mathrm{X}^{\prime \prime}$ is composition set $2(\mathrm{C} 1 \# 2)$. Then, $\mathrm{C} 1 \# 1$ and $\mathrm{C} 1 \# 2$ define the equilibrium compositions at each temperature and ultimately, the binodal curve of the miscibility gap. The critical temperature of the miscibility gap was calculated using the present thermodynamic description, $T_{\mathrm{c}}=1007.4^{\circ} \mathrm{C}$.

The solid phase was modelled with 2 sublattices (SLs) as proposed by Kozlov et al.: ${ }^{17}(\mathrm{Mg})_{0.5}(\mathrm{Si}, \mathrm{Sn})_{0.25}$ allowing $\mathrm{Si}$ and $\mathrm{Sn}$ in the same SL, with a computational convenient SL multiplicity $(0.5 / 0.25)$, yet related to the Wyckoff sites, and two Gibbs energy excess terms to reproduce the miscibility gap.

The isopleth at 66.7 at $\% \mathrm{Mg}$ is, in fact, a quasibinary section due to the congruent melting of both binary compounds $\mathrm{C} 1 \_\mathrm{Mg}_{2} \mathrm{Sn}$ and $\mathrm{C} 1 \_\mathrm{Mg}_{2} \mathrm{Si}$; therefore, it can be read as a binary system with the tie-lines (equilibrium compositions), in theory, in the same plane of the section. However, two remarks are worth mentioning: first, the terminal members of the solid solution are then compounds, $\mathrm{Mg}_{2} \mathrm{Si}$ and $\mathrm{Mg}_{2} \mathrm{Sn}$, and not elements; second, the practical fact of processing samples at a fixed $\mathrm{Mg}$ composition is rare to achieve in real applications and therefore knowledge on neighbouring competing phases is essential. In the manufacturing of TE materials, the relatively high $\mathrm{Mg}$ vapour pressure under processing conditions (leading to $\mathrm{Mg}$ loss and affecting the TE properties) is in practice often compensated for by $\mathrm{Mg}$ excess during mechanical alloying and during annealing. ${ }^{28,29}$ With these practical considerations, the TE material is synthesized, and the blue square in the isothermal representation at $600{ }^{\circ} \mathrm{C}$ shown in Fig. $2 \mathrm{~b}$ indicates the composition of the pellet of the TE material before contacting, $\mathrm{Mg}_{2} \mathrm{Si}_{0.3} \mathrm{Sn}_{0.7}$, within the miscibility gap at a stoichiometry of $66.67 \mathrm{at} \% \mathrm{Mg}$.

\subsection{The $\mathrm{Cu}-\mathrm{Mg}-\mathrm{Si}, \mathrm{Cu}-\mathrm{Mg}-\mathrm{Sn}$ and $\mathrm{Cu}-\mathrm{Si}-\mathrm{Sn}$ systems}

To build up the three ternary systems containing $\mathrm{Cu}$, the following binaries were accepted from the literature: $\mathrm{Cu}-\mathrm{Mg},{ }^{30}$ $\mathrm{Cu}-\mathrm{Sn},{ }^{31}$ and $\mathrm{Cu}-\mathrm{Si}^{32}$ and the calculated diagrams can be seen in Fig. 3a and 4a. Special interest is on the $\mathrm{Cu}_{2} \mathrm{Mg}$ phase due to the experimental evidence of dissolving $\mathrm{Si}$ and $\mathrm{Sn}$, up to $\approx 12$ at $\% \mathrm{Si}$ and $\approx 15$ at $\% \mathrm{Sn}$ at $\approx 500{ }^{\circ} \mathrm{C}$, which in turn would represent a quaternary extension in the $\mathrm{Cu}-\mathrm{Mg}-\mathrm{Si}-\mathrm{Sn}$ system.

The $\mathrm{Cu}_{2} \mathrm{Mg}$ intermediate compound is the prototype for Laves phases of type $\mathrm{C} 15$ with a cubic crystal structure and space group $F d \overline{3} m$. This phase was labelled in this work as: C15_ $\mathrm{Cu}_{2} \mathrm{Mg}$ for the binary, $\mathrm{C} 15 \mathrm{Cu}_{2} \mathrm{MgSi}$ and $\mathrm{C} 15 \mathrm{Cu}_{2} \mathrm{MgSn}$ for the ternary extensions, and C15 for the quaternary extension.

The thermodynamic description for the $\mathrm{Cu}-\mathrm{Mg}-\mathrm{Si}$ system was taken from Zhao et al. $^{33}$ and the calculated isotherm at $600{ }^{\circ} \mathrm{C}$ is presented in Fig. 3b. This section shows mainly two ternary phases, $\tau_{1}-\mathrm{Cu}_{3} \mathrm{Mg}_{2} \mathrm{Si}$ and $\tau_{2}-\mathrm{Cu}_{16} \mathrm{Mg}_{6} \mathrm{Si}_{7}$ as well as the ternary extension $\mathrm{C}_{15} \mathrm{Cu}_{2} \mathrm{MgSi}$ and the liquid phase on the $\mathrm{Mg}$ rich side. There is reported evidence in the literature ${ }^{34}$ of a ternary phase, $\tau_{3}-\left(\mathrm{Cu}_{0.8} \mathrm{Si}_{0.2}\right)_{2}\left(\mathrm{Mg}_{0.88} \mathrm{Cu}_{0.12}\right)$, an order derivative of $\mathrm{C} 15 \_\mathrm{Cu}_{2} \mathrm{MgSi}$ existing at $500{ }^{\circ} \mathrm{C}$ but its temperature of stability and phase relations were not reported so far; and a high temperature polymorph of the mentioned $\tau_{1}-\mathrm{Cu}_{3} \mathrm{Mg}_{2} \mathrm{Si}$, hexagonal $h P 24$ Laves-type $\mathrm{C} 36$ that exists above $870^{\circ} \mathrm{C}$. Following the 


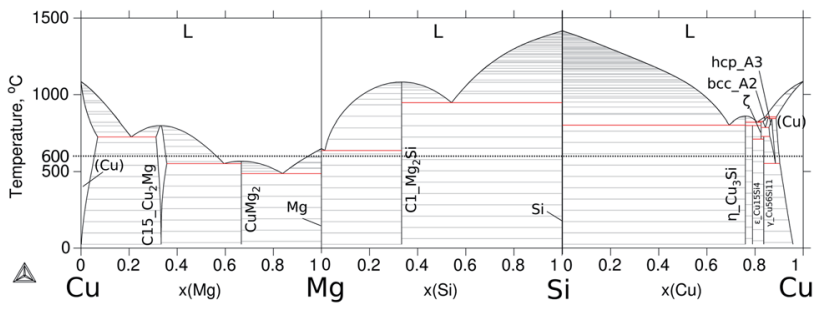

$\mathrm{Cu}$

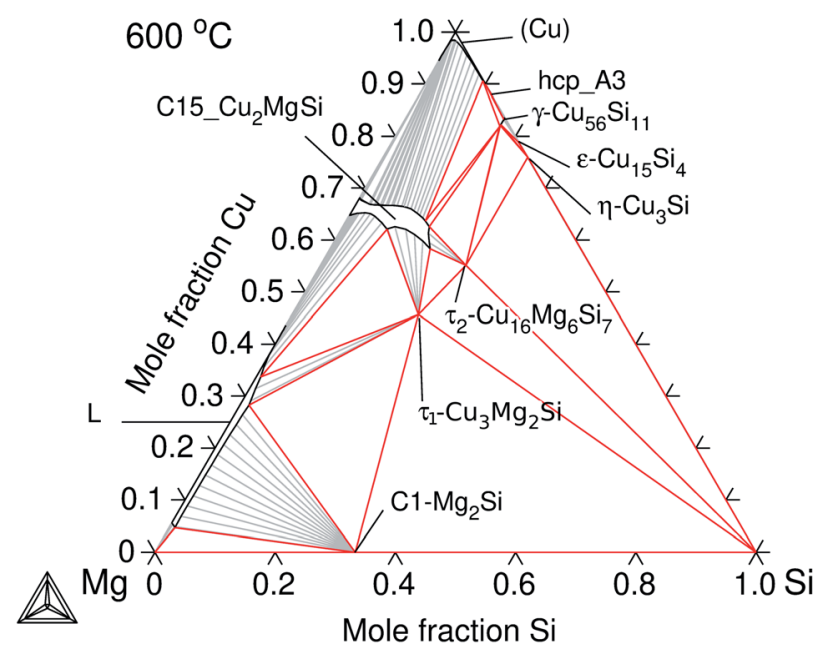

Fig. 3 Calculated equilibrium diagrams for the $\mathrm{Cu}-\mathrm{Mg}-\mathrm{Si}$ system using Thermo-Calc software $2021 \mathrm{a}^{27}$ and the assembled thermodynamic database for this work. (a) Binary phase diagrams, $\mathrm{Cu}-\mathrm{Mg}^{30}$ $\mathrm{Mg}-\mathrm{Si}^{18}$ and $\mathrm{Si}-\mathrm{Cu}^{32}$ (b) Isothermal section at $600{ }^{\circ} \mathrm{C}$ of ternary $\mathrm{Cu}-$ $\mathrm{Mg}-\mathrm{Si}$ with parameters from Zhao et al. ${ }^{33}$

thermodynamic models of Zhao et al. ${ }^{33}$, the former was treated together with $\mathrm{C} 15 \_\mathrm{Cu}_{2} \mathrm{MgSi}$ and the latter was treated as one phase with $\tau_{1}-\mathrm{Cu}_{3} \mathrm{Mg}_{2} \mathrm{Si}$.

The modelling of ternary $\mathrm{Cu}-\mathrm{Si}-\mathrm{Sn}$ was done by extrapolation from the respective binaries since no ternary phase is known to form in this system. The calculated phase diagrams for the binaries and the isothermal section at $600{ }^{\circ} \mathrm{C}$ are presented in Fig. 4.

The equilibrium in the isothermal section is dominated by the ternary extension of the bcc_A2 phase on the Cu-rich side and the liquid phase on the Sn-rich side. Finally, the description for the $\mathrm{Cu}-\mathrm{Mg}-\mathrm{Sn}$ system is presented in Section 4.1.

A summary of the thermodynamic models used for relevant phases for the interpretation of the present results is given in Table 1, while the complete thermodynamic description and database file (TDB) can be found in the ESI. $\dagger$

\section{Experimental}

The subsequent thermodynamic and kinetic analysis of the contacts can't be understood without the experimental details; therefore we summarise in this section relevant synthesis
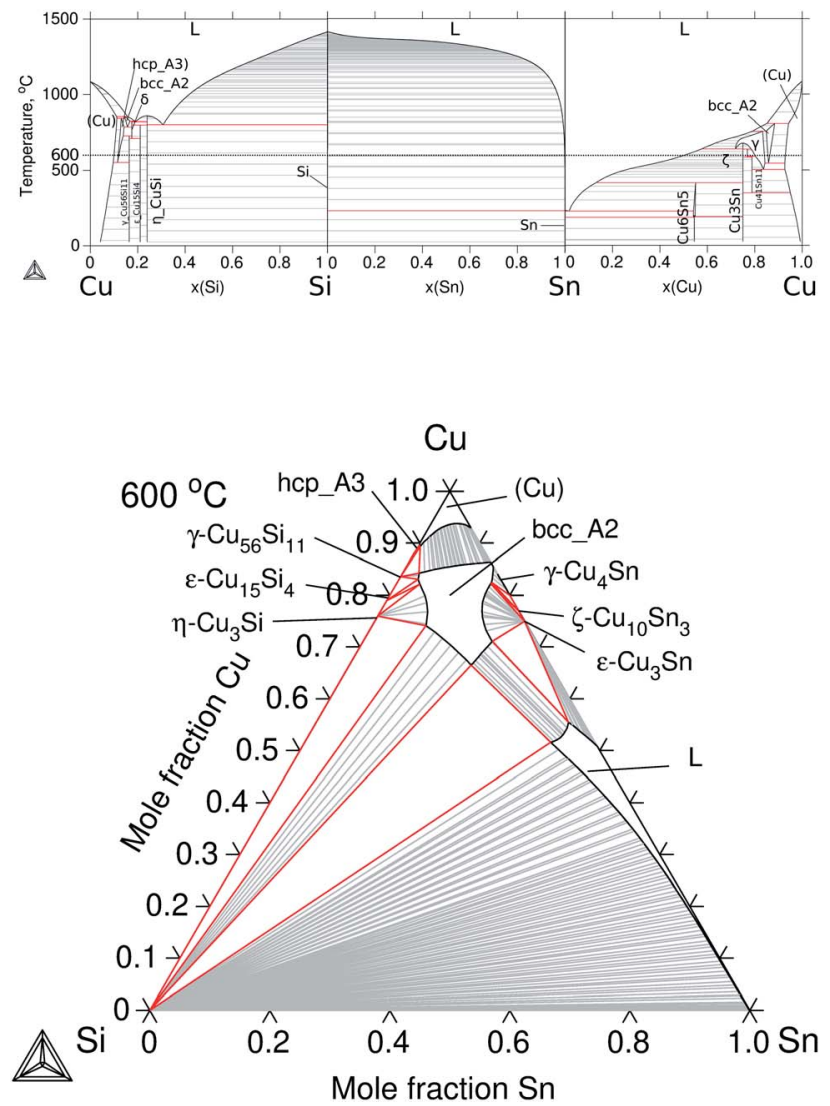

Fig. 4 Calculated equilibrium diagrams for the $\mathrm{Cu}-\mathrm{Si}-\mathrm{Sn}$ system using Thermo-Calc software $2021 \mathrm{a}^{27}$ and the assembled thermodynamic database for this work. (a) Binary phase diagrams, $\mathrm{Cu}-\mathrm{Si}^{32} \mathrm{Si}-$ $\mathrm{Sn}^{20}$ and $\mathrm{Sn}-\mathrm{Cu}^{31}$ (b) Isothermal section at $600{ }^{\circ} \mathrm{C}$ of ternary $\mathrm{Cu}-\mathrm{Si}-$ Sn.

parameters associated with the present calculations, while a detailed description can be found in the work of Ayachi et $a .^{10}$

The contacts between the TE material and $\mathrm{Cu}$ were fabricated in two steps: the synthesis of TE pellets and the contacting with $\mathrm{Cu}$. First, the TE pellets were synthesized from mechanically alloyed powders with the starting compositions of $\mathrm{Mg}_{2.06} \mathrm{Si}_{0.3} \mathrm{Sn}_{0.665} \mathrm{Bi}_{0.035}$ for $\mathrm{n}$-type and $\mathrm{Mg}_{1.97} \mathrm{Li}_{0.03} \mathrm{Si}_{0.3} \mathrm{Sn}_{0.7}$ for p-type. The dopant elements, $\mathrm{Bi}$ and $\mathrm{Li}$, were not included in the present thermodynamic models as explained in Section 4.2.4. The alloyed powders were consolidated in a direct-current sinter press at $700{ }^{\circ} \mathrm{C}$ for $20 \mathrm{~min}$ and $10 \mathrm{~min}$ for $\mathrm{n}$ - and p-type, respectively, under vacuum with a pressure of $66 \mathrm{MPa}$, and a $1 \mathrm{~K} \mathrm{~s}^{-1}$ heating rate using a graphite die.

Second, the pellets were contacted in the same facility with $\mathrm{Cu}$ foil of $\approx 50 \mu \mathrm{m}$ thickness in direct contact with the graphite pistons on the top and bottom allowing the electrical current to flow through the electrodes and the sample. The joining was done at $600{ }^{\circ} \mathrm{C}$ for $10 \mathrm{~min}$. The contacting temperature was chosen to be approximately the half of the melting temperature of the electrode $\left(T_{\mathrm{Cu}}^{\mathrm{m}}=1085^{\circ} \mathrm{C}\right)$. The TE properties of the pellets and contacts can be found in the literature, ref. 8.

The cross sections of the contacted samples were metallographically prepared for microstructure inspection and chemical analysis using a Scanning Electron Microscope (SEM), Zeiss 
Table 1 Crystallographic information and thermodynamic sublattice (SL) model used for modelling the phases of major interest in the present investigation on $\mathrm{Mg}_{2}\left(\mathrm{Si}_{0.3} \mathrm{Sn}_{0.7}\right) / \mathrm{Cu}$ joints

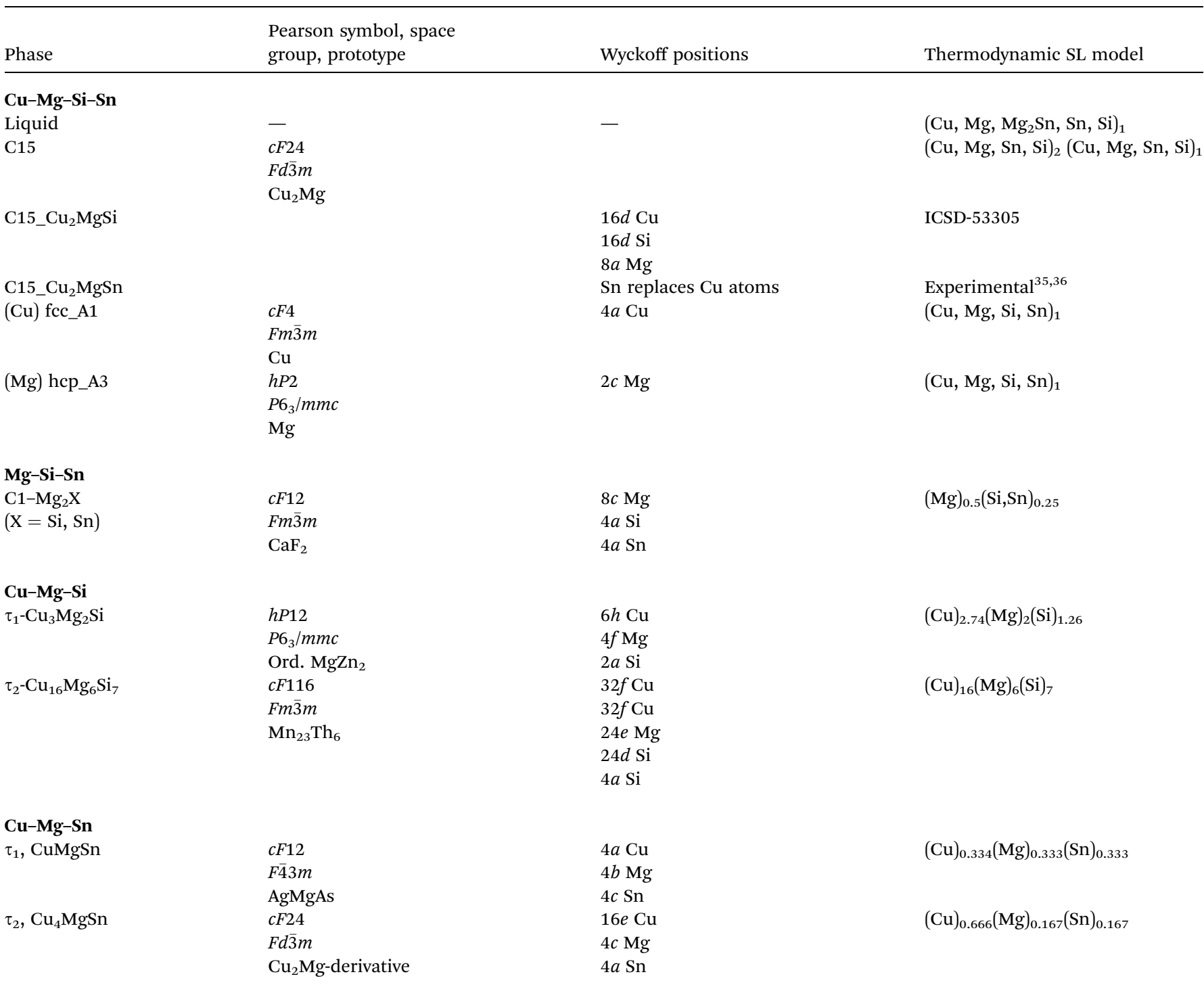

Ultra 55 equipped with an energy-dispersive X-ray spectroscopy (EDX) detector with a $15 \mathrm{kV}$ acceleration voltage and a resulting spatial resolution of $\approx 2 \mu \mathrm{m}$.

The annealing of the contacts was done for 1 week at $450{ }^{\circ} \mathrm{C}$ in sealed quartz ampules under an argon atmosphere, and the samples were coated with a thick BN layer to minimize $\mathrm{Mg}$ evaporation during the thermal treatment.

\section{Results and discussion}

\subsection{Buildup of the Gibbs energy database}

The constitutive subsystems of quaternary $\mathrm{Cu}-\mathrm{Mg}-\mathrm{Si}-\mathrm{Sn}$ are presented in Section 2.2; however, one of the most significant systems is the $\mathrm{Cu}-\mathrm{Mg}-\mathrm{Sn}$ ternary, which will be introduced here in detail, as well as, the quaternary isotherm at $600{ }^{\circ} \mathrm{C}$.

The set of Gibbs energies for $\mathrm{Cu}-\mathrm{Mg}-\mathrm{Sn}$ was built using parameters from Miettinen et al. ${ }^{37}$ to model the excess energy of the liquid and the ternary phases, $\tau_{1}-\mathrm{CuMgSn}$ and $\tau_{2}-\mathrm{Cu}_{4} \mathrm{MgSn}$, whereas for the ternary extension $\mathrm{C} 15 \_\mathrm{Cu}_{2} \mathrm{MgSn}$, the solubility of Sn was adjusted in this work to reproduce the results of Vicente et al. ${ }^{35}$ at $525{ }^{\circ} \mathrm{C}$. The calculated binaries and isothermal section at $600{ }^{\circ} \mathrm{C}$ are presented in Fig. 5 . It can be seen that $\mathrm{Cu}$ dissolves up to $\approx 8$ at $\% \mathrm{Mg}$ and $\mathrm{Sn}$ in the $(\mathrm{Cu})$ solid solution but the solubility of $\mathrm{Cu}$ in $\mathrm{Mg}$ and $\mathrm{Sn}$ is negligible. A small solubility of $\mathrm{Cu}$ in $\mathrm{Mg}_{2} \mathrm{Sn}\left(0.6-1.4\right.$ at\% $\mathrm{Cu}$ ) and of $\mathrm{Sn}$ in $\mathrm{CuMg}_{2}$ (2.2 at\% $\mathrm{Sn})$ have been reported $^{35}$ but not considered in the present modelling. The calculated isothermal section indicates that C15_Cu $\mathrm{Cu}_{2} \mathrm{MgSn}$ is in equilibrium with the ternary $\tau_{2}-\mathrm{Cu}_{4} \mathrm{MgSn}$, the binary $\mathrm{C}_{-} \mathrm{Mg}_{2} \mathrm{Sn}$, the $(\mathrm{Cu})$ terminal solid solution and the liquid phase on the Sn-rich and $\mathrm{Mg}$-rich sides.

The quaternary extension of the $\mathrm{C} 15$ phase was modelled with 2SL as: (Cu, Mg, Si, Sn $)_{2}(\mathrm{Cu}, \mathrm{Mg}, \mathrm{Si}, \mathrm{Sn})$ allowing the four elements in all SLs. Parameters for this phase were estimated in this work based on the assessment of Zhao et al. ${ }^{33}$. In contrast to the ternaries, the representation of a quaternary phase diagram is more challenging; however, a useful plot is a hatched 

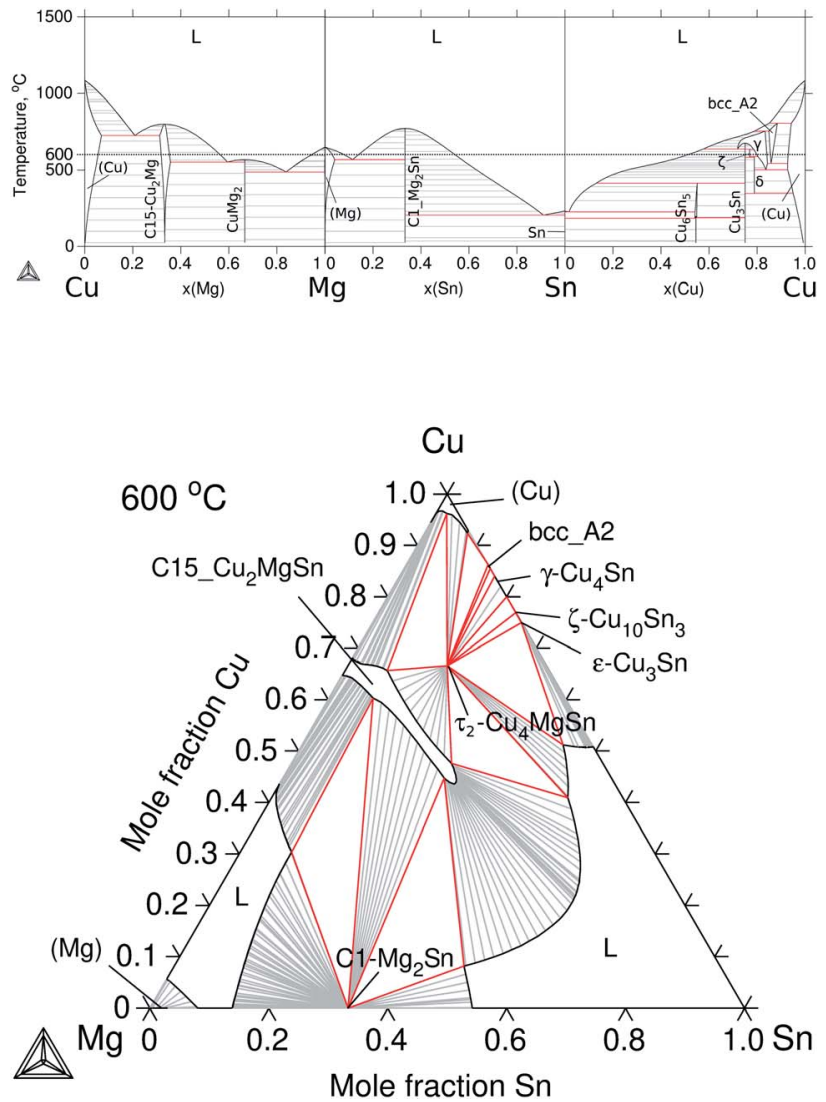

Fig. 5 Calculated equilibrium diagrams for the $\mathrm{Cu}-\mathrm{Mg}-\mathrm{Sn}$ system using Thermo-Calc software $2021 \mathrm{a}^{27}$ and the assembled thermodynamic database for this work. (a) Binary phase diagrams, $\mathrm{Cu}-\mathrm{Mg}{ }^{30}$ $\mathrm{Mg}-\mathrm{Sn}^{26}$ and $\mathrm{Sn}-\mathrm{Cu}^{31}(\mathrm{~b})$ Isothermal section at $600^{\circ} \mathrm{C}$ of ternary $\mathrm{Cu}-$ $\mathrm{Mg}-\mathrm{Sn}$.

tetrahedron for a given temperature as shown in Fig. 6 for $600{ }^{\circ} \mathrm{C}$. The isothermal regular tetrahedron has four triangular faces made of isothermal sections of the constitutive ternary systems as indicated in the sketch at the low right corner of the same figure.

\subsection{Thermodynamic calculations with the constructed database}

4.2.1 Interpretation of the junctions. We apply thermodynamic calculations to gain understanding of the phenomena taking place near the original interface when contacting the TE material and a selected metallic electrode, in this case $\mathrm{Mg}_{2}$ $\mathrm{Si}_{0.3} \mathrm{Sn}_{0.7}$ with $\mathrm{Cu}$, as indicated in the scheme of Fig. 7. In the initial stage before the contacting process starts $(t=0 \mathrm{~min})$, the pellet of TE material with composition $\mathrm{Mg}_{2}\left(\mathrm{Si}_{0.3} \mathrm{Sn}_{0.7}\right)$ evidences a single phase microstructure under SEM-EDX and XRD analyses, in contradiction with the equilibrium diagram (c.f. blue square in Fig. 2b) that for this composition indicates a phase separation within the miscibility gap. One possible underlying reason for this discrepancy can be related to the interfacial energies and strain effects, very likely to be significant in mechanically alloyed and sintered samples, but not taken into account in the present thermodynamic model.
They represent additional contributions to the Gibbs energy of the phase and can significantly increase the solubility or, in other words, suppress the miscibility gap. Further investigation on this feature is ongoing, although the first insights into the miscibility gap in the $\mathrm{Mg}_{2} \mathrm{Si}-\mathrm{Mg}_{2} \mathrm{Sn}$ system based on ab intio studies combined with microstructure simulations ${ }^{38}$ and experimental studies $^{25}$ can be found in the literature. Nonetheless, we show that the current thermodynamic description can effectively indicate the constitution of the resulting intermediate layers and can help to elucidate the microstructure evolution in the IZ.

The $\mathrm{Mg}_{2}\left(\mathrm{Si}_{0.3} \mathrm{Sn}_{0.7}\right) / \mathrm{Cu}$ contacts are semiconductor/metal junctions, in particular, ohmic contacts showing a linear current-voltage behaviour. Therefore, one important parameter is the electrical contact resistance characterized in previous work, ${ }^{10}$ while here we deal with the phase identification of the interlayers that evolve in the IZ. The selection of $\mathrm{Cu}$ as the electrode material was done based on the low specific contact resistance $\left(<10 \mu \Omega \mathrm{cm}^{2}\right)$, similar coefficients of thermal expansion (CTE) for the TE legs $\left(\mathrm{Mg}_{2}\left(\mathrm{Si}_{0.3} \mathrm{Sn}_{0.7}\right)=17.5 \times 10^{-6} \mathrm{~K}^{-1}\right.$ (ref. 39)) and the electrode $\left(\mathrm{Cu}=17.0 \times 10^{-6} \mathrm{~K}^{-1}\right.$ (ref. 40)), and good bonding to the TE material. ${ }^{10}$ More precisely, the concept of bonding, elsewhere called adhesion, refers to the diffusionreaction phenomena responsible for the phase transformations leading to a layered growth of intermediate phases (interlayers) in the IZ. The identification of the grown interlayers is crucial for further correlations with the specific contact resistance of the junctions, the TE properties of the legs, and the long-term functional stability of the connections.

The sequence of possible stable phases to be formed in the IZ can be calculated in the quaternary equilibrium diagram. A particularly useful section is $\mathrm{Cu}-\mathrm{Mg}_{2} \mathrm{Sn}-\mathrm{Mg}_{2} \mathrm{Si}$ at $600{ }^{\circ} \mathrm{C}$ as presented in Fig. 8a, and this diagram represents a plane within the isothermal composition tetrahedron as shown schematically on the right side of the figure. The light-gray dotted line in the phase diagram indicates the contacted couple $\mathrm{Mg}_{2}\left(\mathrm{Si}_{0.3}-\right.$ $\left.\mathrm{Sn}_{0.7}\right) / \mathrm{Cu}$ and the mass balance is fulfilled along this line, but it should not be confused with the diffusion path (or the reaction path). This section clearly shows the C15 single-phase field extending between the ternaries $\mathrm{C} 15 \_\mathrm{Cu}_{2} \mathrm{MgSn}$ and $\mathrm{C15} \mathrm{Cu}_{2}-$ MgSi establishing the quaternary extension of the C15 phase (highlighted in beige).

The contacted samples can be modeled as diffusion-reaction couples, where at elevated temperatures, atomic diffusion towards and reaction at interfaces take place, in general, one of them being the dominating mechanism. Transformations at the interface are heterogeneous solid-state reactions that occur via nucleation and growth of new phases and interfaces (phase boundary migration). An important assumption in diffusion couples is the local equilibrium at the interfaces, meaning that the chemical potential of the species has the same value on both sides of a given interface. This assumption allows the use of the equilibrium diagrams to correlate the order of the product layers, their morphology and their composition. However, in many cases supersaturated regions occur near the interfaces leading to off-equilibrium; in particular, if a liquid phase is 


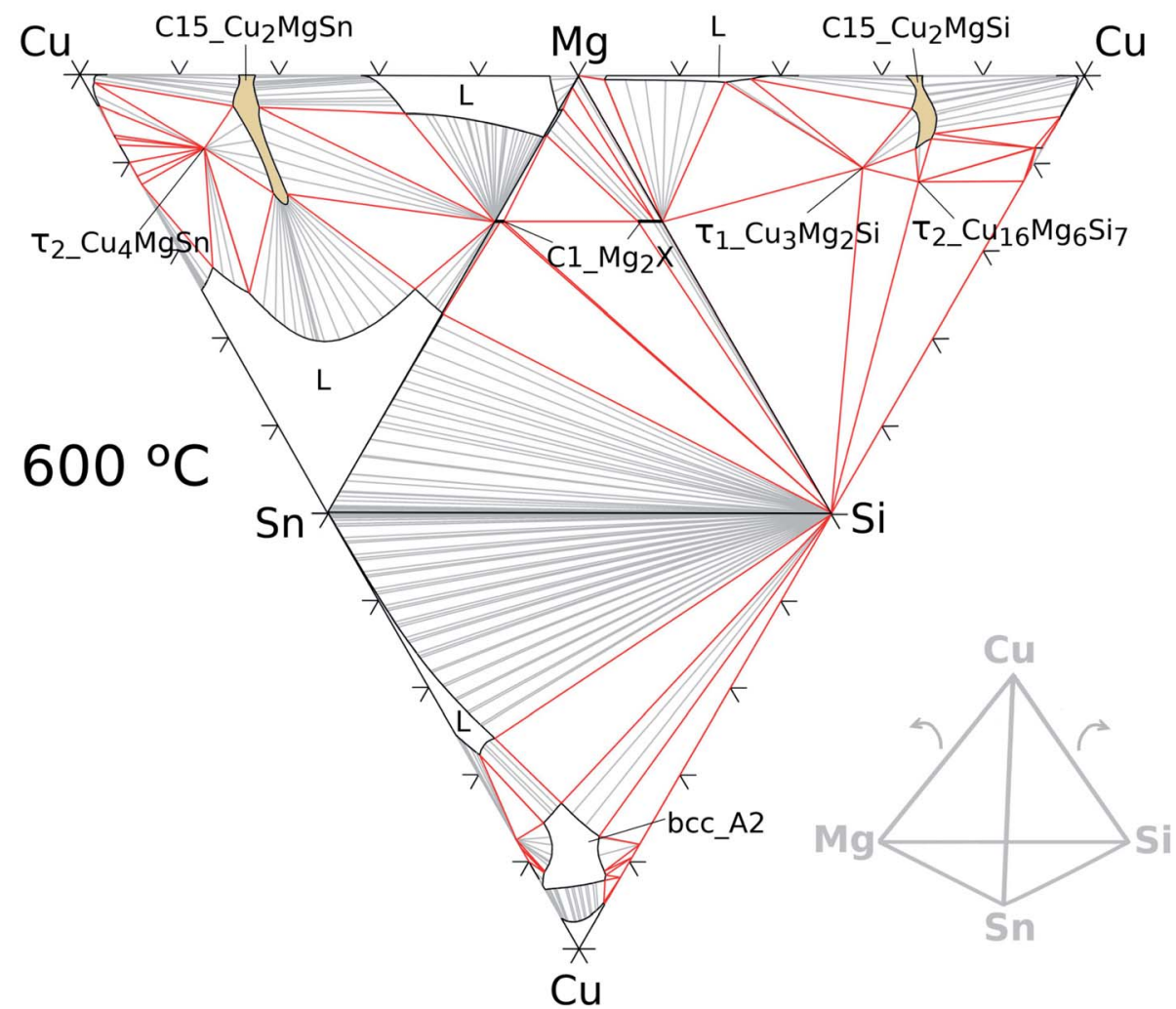

Fig. 6 Hatched isothermal tetrahedron at $600{ }^{\circ} \mathrm{C}$ for the $\mathrm{Cu}-\mathrm{Mg}-\mathrm{Si}-\mathrm{Sn}$ system formed by calculated isotherms of the constitutive ternary systems as shown in the sketch on the right.

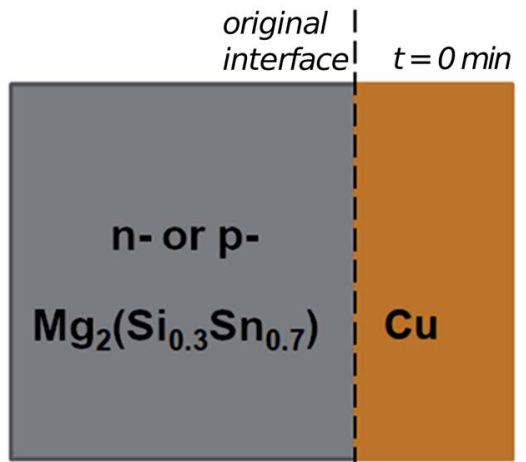

Fig. 7 Schematic representation of the two materials before contacting.

present the assumptions for solid-solid diffusion/reaction should be carefully considered. ${ }^{41}$

In the initial situation (Fig. 7) only one interface exists between $\mathrm{Mg}_{2}\left(\mathrm{Si}_{0.3} \mathrm{Sn}_{0.7}\right)$ and $\mathrm{Cu}$, i.e. the original interface where the reaction starts. As mentioned before, $\mathrm{Mg}_{2}\left(\mathrm{Si}_{0.3} \mathrm{Sn}_{0.7}\right)$ is a homogeneous pellet with no microscopic dephasing, $7 \pm 3 \mu \mathrm{m}$ grain size and a pellet density of $\geq 97 \%$ (after the powder consolidation at $\left.700{ }^{\circ} \mathrm{C}\right) .{ }^{42}$. In the final situation, after $10 \mathrm{~min}$ of joining at $600{ }^{\circ} \mathrm{C}$ in a direct sinter press, a reacted IZ can be observed with several new interfaces. A typical microstructure of the IZ is presented in Fig. $8 \mathrm{~b}$, and the cross section of the junction was imaged and chemically analysed with SEM/EDX microscopy. Four layers can be noted between the TE material and $\mathrm{Cu}$. The composition of the interlayers is related to the phase diagram in the same figure as follows. The composition of $\mathrm{Cu}$ varies across the IZ decreasing towards $\mathrm{Mg}_{2}\left(\mathrm{Si}_{0.3} \mathrm{Sn}_{0.7}\right)$, and this can be visualized on the phase diagram by following the gray dotted line. However, it is not possible to confirm only from the inspection of the final microstructure which phase nucleates and grows first at the original interface; in that case growth-kinetic experiments are required which can be confirmed by diffusion calculations if the diffusivity databases are available. ${ }^{12}$ Nonetheless, it is possible to deduce from the phase diagram that the initial interface in the $\mathrm{Mg}_{2}\left(\mathrm{Si}_{0.3} \mathrm{Sn}_{0.7}\right) / \mathrm{Cu}$ couple is not in equilibrium since several intermediate phases exist between the couple ends, and are expected to grow in the IZ. We can conjecture a possible initial scenario, where $\mathrm{Mg}$ diffuses into the $\mathrm{Cu}$ electrode to form the $(\mathrm{Cu})$ solid solution based on the higher solubility of $\mathrm{Mg}$ in fcc-Cu than $\mathrm{Cu}$ in $\mathrm{Mg}_{2} \mathrm{Sn}$ or $\mathrm{Mg}_{2} \mathrm{Si}$. Afterwards, the saturation of $(\mathrm{Cu})$ solid solution occurs and $\mathrm{C}_{15} \mathrm{Cu}_{2} \mathrm{Mg}$ nucleates and grows. Thus, in Fig. 8a the diagram is read from the Cu-rich corner down to $\mathrm{Mg}_{2}(-$ $\left.\mathrm{Si}_{0.3} \mathrm{Sn}_{0.7}\right)$ following the gray dotted line crossing several 2- and 3-phase fields with decreasing $\mathrm{Cu}$ composition, but only one single-phase field of $\mathrm{C} 15$ around 60 to 56 at $\% \mathrm{Cu}$.

The EDX composition analysis in Fig. $8 \mathrm{~b}$ and data in Table 1 from Ayachi et al. ${ }^{10}$ show the phases $\tau_{1}-\mathrm{Cu}_{3} \mathrm{Mg}_{2} \mathrm{Si}$ (Cu51 Mg33.3 Si15 Sn0.7, at\%), C1_Mg 2 Sn (Cu1 Mg64 Sn33 Bi2, at\%) and C15 
(a)<smiles></smiles>

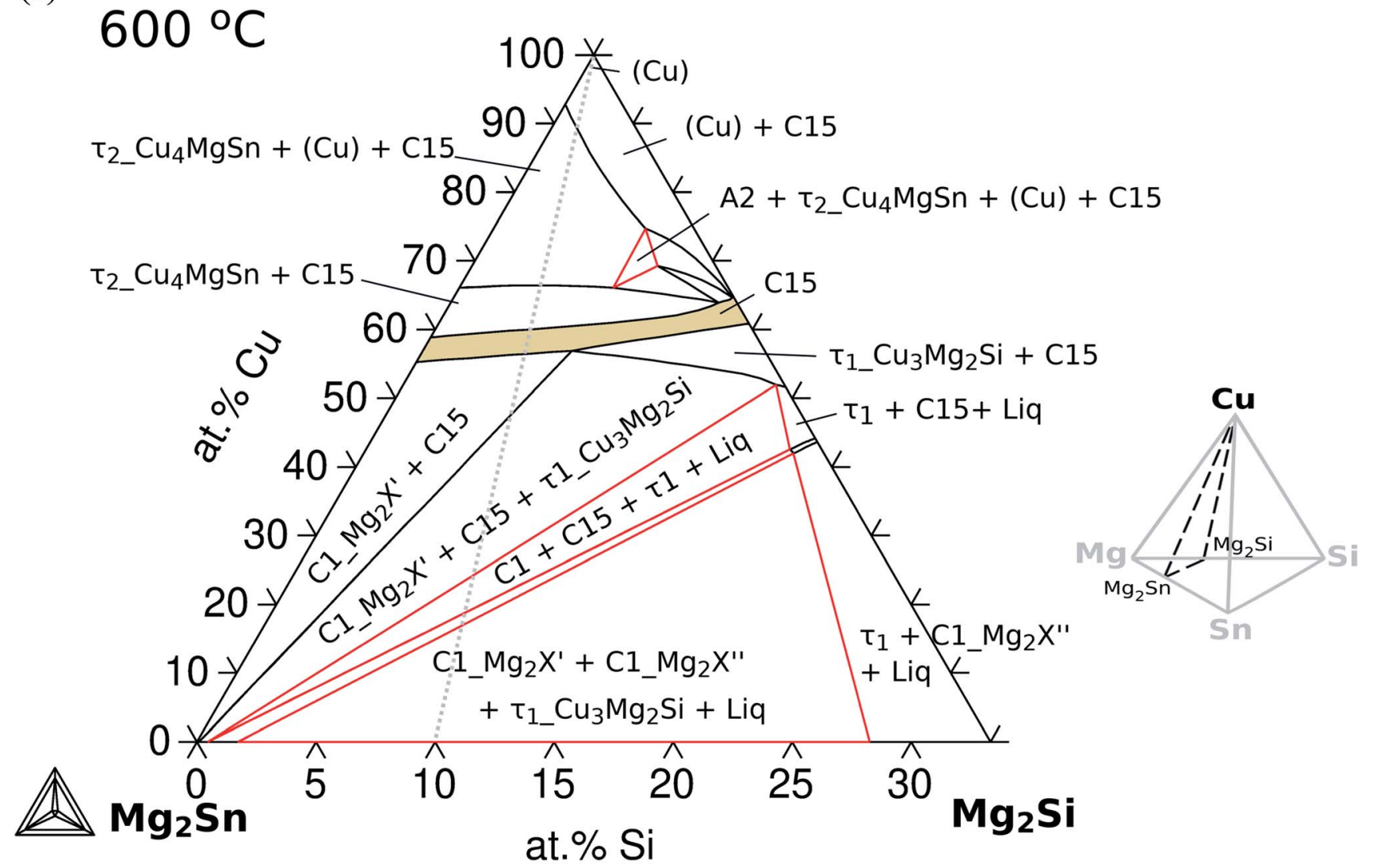

(b)
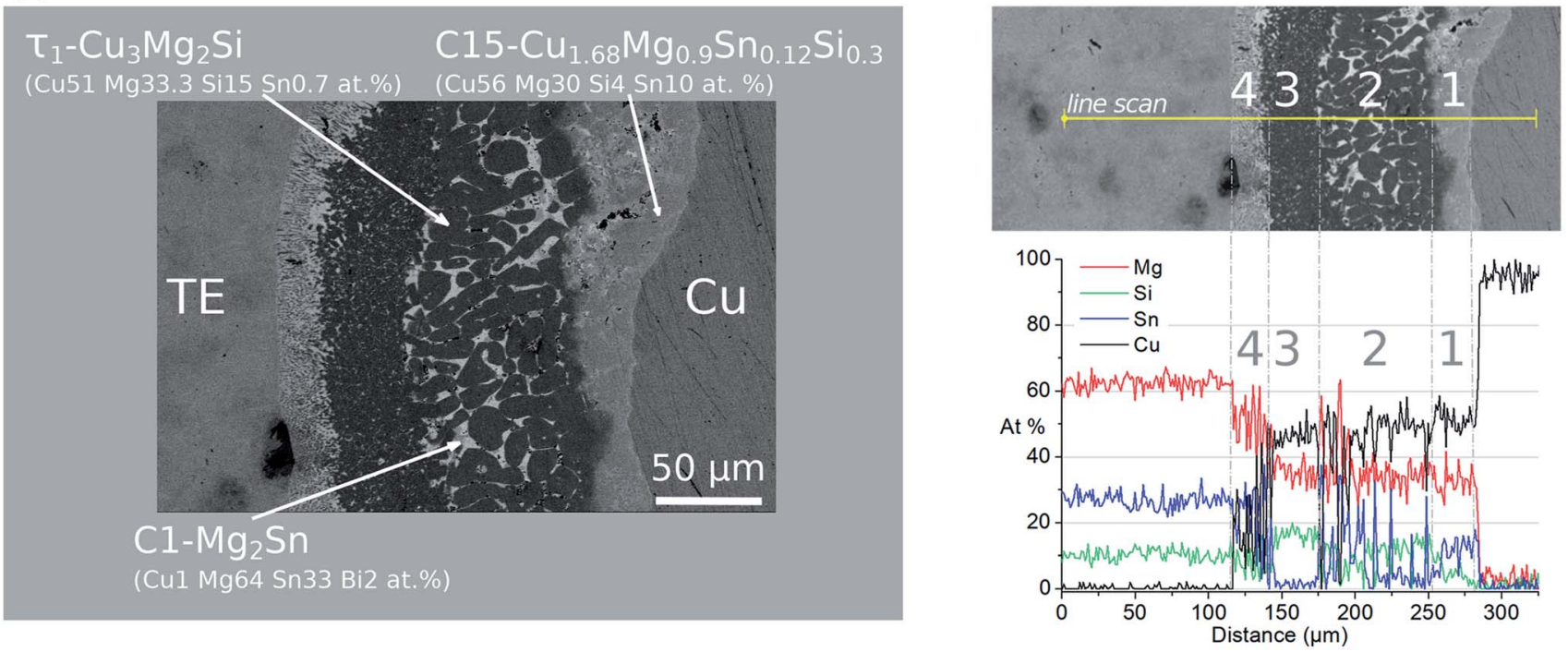

Fig. 8 Calculated section of the quaternary phase diagram and experimental results. (a) Calculated $\mathrm{Mg}_{2} \mathrm{Si}-\mathrm{Mg}_{2} \mathrm{Si}-\mathrm{Cu}$ section of the isothermal tetrahedron at $600{ }^{\circ} \mathrm{C}$ using the present thermodynamic database; and scheme of the section within the composition tetrahedron. (b) SEM-BSE micrograph of a typical microstructure of the $\mathrm{IZ}$ in $\mathrm{Mg}_{2} \mathrm{Si}_{0.3} \mathrm{Sn}_{0.7} / \mathrm{Cu}$ junctions contacted at $600{ }^{\circ} \mathrm{C}$ and EDX line scan results across the $\mathrm{IZ}$.

(Cu56 Mg30 Si4 Sn10, at\%). The latter was initially associated with the ternary extension C15_Cu 2 MgSn (Cu52 Mg33 Sn15 or $\gamma-\mathrm{Cu}_{1.55} \mathrm{MgSn}_{0.45}$ in ref. 10) due to the low Si content close to the EDX detection limit. However, the thermodynamic calculations confirm the composition of the quaternary extension, the C15 phase (see Fig. 9 2nd column, figure explanation hereunder), and show excellent agreement with the experimental observations. The reacted IZ seems to have evolved up to the 3-phase region, $\mathrm{C} 1 \_\mathrm{Mg}_{2} \mathrm{X}^{\prime}+\mathrm{C} 15+\tau_{1}-\mathrm{Cu}_{3} \mathrm{Mg}_{2} \mathrm{Si}$, in the phase diagram but the round shape precipitate morphology and wavy 


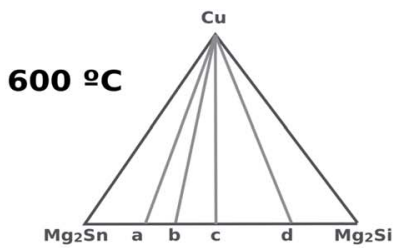

a. $\mathrm{Mg}_{2} \mathrm{Si}_{0.3} \mathrm{Sn}_{0.7} / \mathrm{Cu}$

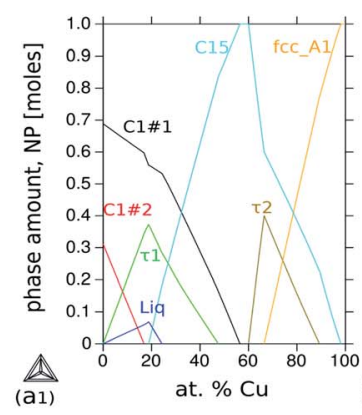

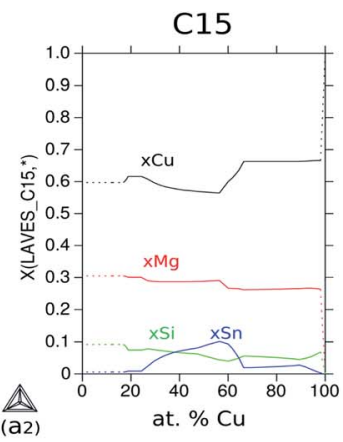

$\mathrm{C} 1 \mathrm{Mg}_{2} \times(\mathrm{C} 1 \# 1 ; \mathrm{C} 1 \# 2)$
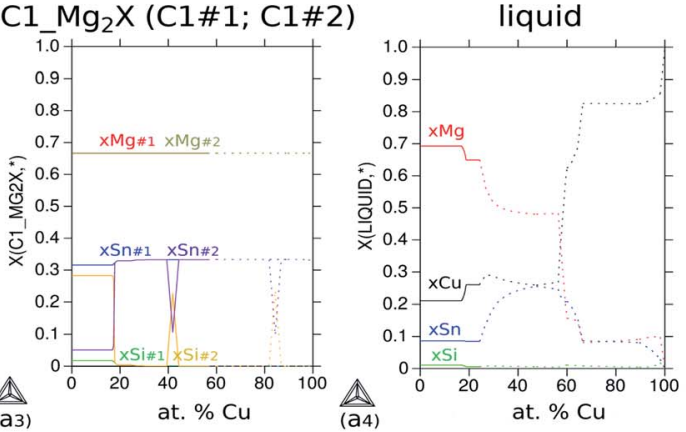

b. $\mathrm{Mg}_{2} \mathrm{Si}_{0.4} \mathrm{Sn}_{0.6} / \mathrm{Cu}$
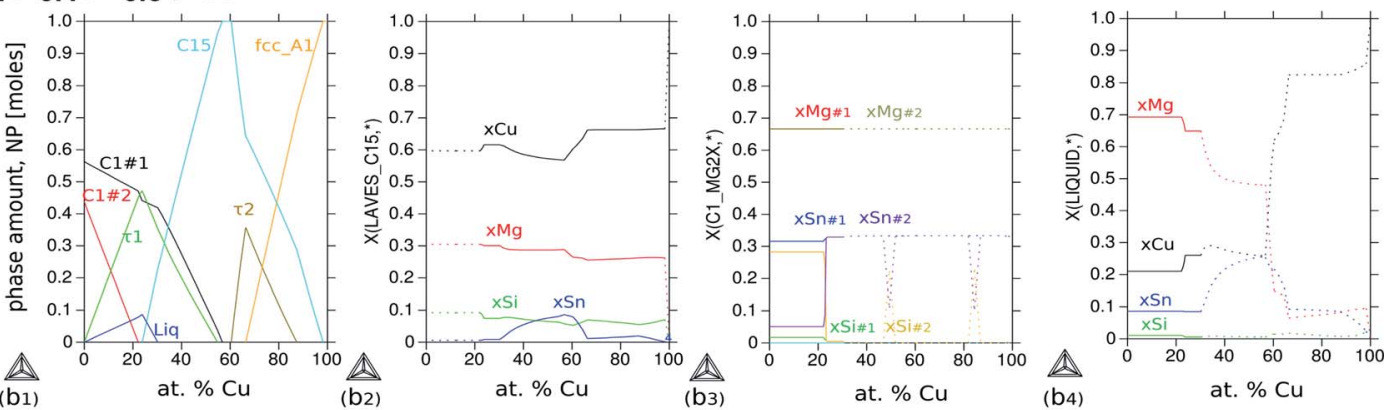

\section{c. $\mathrm{Mg}_{2} \mathrm{Si}_{0.5} \mathrm{Sn}_{0.5} / \mathrm{Cu}$}
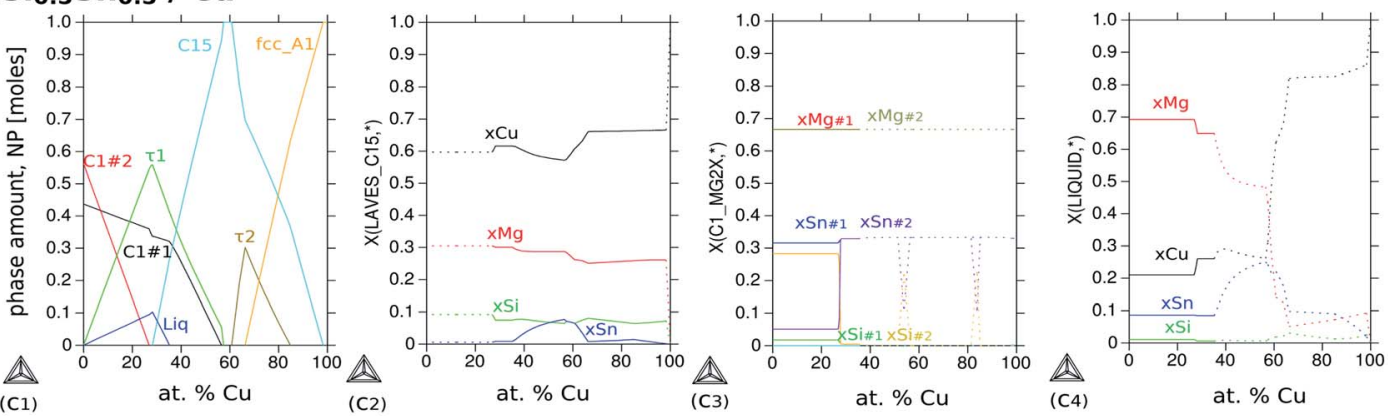

\section{d. $\mathrm{Mg}_{2} \mathrm{Si}_{0.7} \mathrm{Sn}_{0.3} / \mathrm{Cu}$}
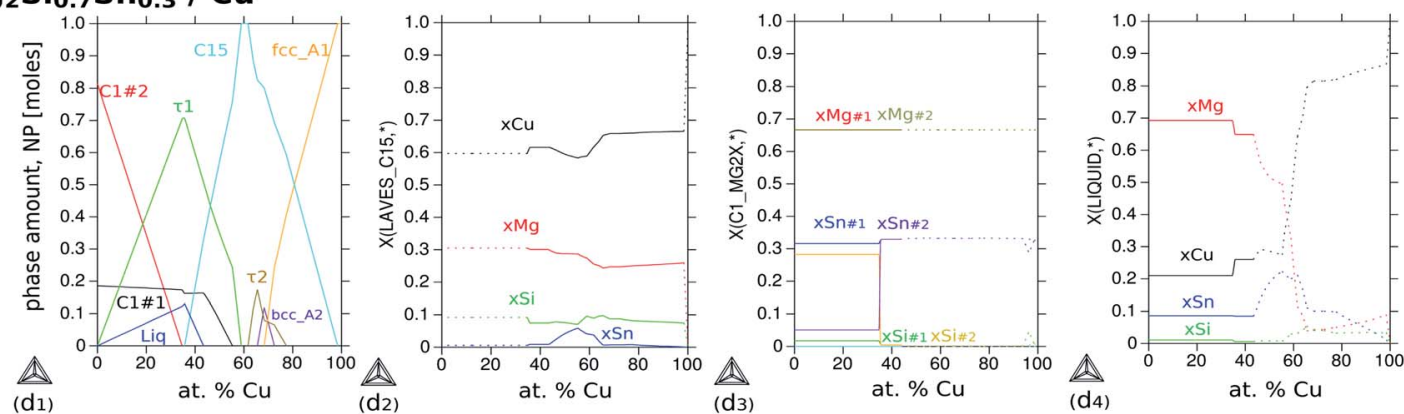

Fig. 9 Calculated diagrams at $600{ }^{\circ} \mathrm{C}$ with varying Cu composition for different $\mathrm{Si} / \mathrm{Sn}$ ratios in the TE material: (a) $\mathrm{Si}_{0.3} \mathrm{Sn}_{0.7}$, (b) $\mathrm{Si}_{0.4} \mathrm{Sn}_{0.6}$, (c) $\mathrm{Si}_{0.5} \mathrm{Sn}_{0.5}$, and (d) $\mathrm{Si}_{0.7} \mathrm{Sn}_{0.3}$, indicating the phase amount and elemental distribution in C15, C1_Mg $\mathrm{X}$ (C1\#1 Sn-rich, C1\#2 Si-rich) and liquid. Dashed lines indicate metastability regions. 
interfaces resemble the liquid phase, being possible to have localized composition gradients with the reduced $\mathrm{Cu}$ content shifting the equilibrium to the 4-phase field, $\mathrm{C} 1 \mathrm{Mg}_{2} \mathrm{X}^{\prime}+\mathrm{C} 15+$ $\tau_{1}-\mathrm{Cu}_{3} \mathrm{Mg}_{2} \mathrm{Si}+$ liquid, as indicated by the phase diagram. In particular, these regions could be located around the precipitates of $\tau_{1}$ and due to the high $\mathrm{Mg}$ content of the liquid phase ( $c f$. Fig. 9 th column) are hardly distinguishable in the dark areas on the SEM/BSE micrograph. In this and other assembles, the presence of liquid in the IZ is highly important and can be anticipated by thermodynamic calculations using an equilibrium description.

It is important to highlight that the section $\mathrm{Mg}_{2} \mathrm{Sn}-\mathrm{Mg}_{2} \mathrm{Si}-\mathrm{Cu}$ does not show tie-lines since they are not necessarily on the same plane of the section; as a result, the amount of each phase in the respective fields cannot be obtained from this diagram. For phase quantification, another diagram is more suitable to indicate the amount of each phase as a function of $\mathrm{Cu}$ content (NP- $x \mathrm{Cu}$ ) as presented in Fig. 9. All diagrams were calculated for $600{ }^{\circ} \mathrm{C}$ varying the composition of $\mathrm{Cu}$ and setting the composition of the TE material, i.e. along the gray lines a-d schematically indicated at the top. The rows correspond to different compositions of the TE material within the solid solution, thus, with increasing $\mathrm{Si}$ to $\mathrm{Sn}$ composition ratio, $\mathrm{Si} / \mathrm{Sn}=0.3 / 0.7$ (a), $0.4 / 0.6$ (b), 0.5/0.5 (c) and 0.7/0.3 (d). The first column shows the diagrams of phase fraction versus composition of $\mathrm{Cu}$, and the following columns show the distribution of the elements as a function of $\mathrm{Cu}$ composition in three phases of interest: C15 (2nd column), C1_ $\mathrm{Mg}_{2} \mathrm{X}$ (3rd column) and liquid (4th column).

The diagram (a1) shows the fraction of each phase in equilibrium when the $\mathrm{Cu}$ content decreases from 100 to 0 at\%, in correlation with the phase fields in Fig. 8a. With this diagram, we want to address three aspects of the final microstructure: (1) the composition of the quaternary extension C15; (2) the composition of the liquid in the 4-phase field; (3) the absence of $\tau_{2}-\mathrm{Cu}_{4} \mathrm{MgSn}$ in the final microstructure.

First, the composition of C15 in Fig. 9(a2) indicates slightly less $\mathrm{Si}$ than $\mathrm{Sn}$ between $\approx 40$ and $60 \mathrm{at} \% \mathrm{Cu}$ in agreement with our EDX analysis. It can also be seen, along the 2 nd column, how $\mathrm{Si}$ and $\mathrm{Sn}$ contents in $\mathrm{C} 15$ vary with the $\mathrm{Si} / \mathrm{Sn}$ ratio in the TE material. The second point is to address the composition of the liquid phase that might form surrounding the black round precipitates of $\tau_{1}$, in Fig. 9(a4). The liquid phase coexisting in the 4-phase field contains mainly $\mathrm{Mg}$ and $\mathrm{Cu}$ dissolving up to $\approx 8$ at $\% \mathrm{Sn}$ and $\leq 1$ at $\% \mathrm{Si}$; therefore it would appear as a dark region in the BSE imaging (see also the $\mathrm{Mg}$ side in Fig. 6). Finally, the absence of $\tau_{2}-\mathrm{Cu}_{4} \mathrm{MgSn}$ in the final microstructure can be explained by observing Fig. 9(a1) and the amount of $\tau_{2}$ is always about $20 \%$ less than that of $\mathrm{C} 15$ for all $\mathrm{Cu}$ compositions; alternatively, it might be a phase with an incubation time larger than 10 min before it starts to grow, and it can have a slower growth rate than $\mathrm{C} 15$, and/or local variations in composition shift the equilibrium outside the plane $\mathrm{Cu}-\mathrm{Mg}_{2} \mathrm{Si}-\mathrm{Mg}_{2} \mathrm{Sn}$, i.e. the diffusion path is not necessarily in this plane.

Coming back to Fig. 8a, we highlight the 2-phase equilibrium, $\mathrm{C} 15+\mathrm{C} 1 \_\mathrm{Mg}_{2} \mathrm{X}^{\prime}$, at $\leq 55$ at $\% \mathrm{Cu}$, where the $\mathrm{C} 15$ phase can exist in equilibrium with $\mathrm{Mg}_{2} \mathrm{Sn}$ possibly inducing phase separation in the TE material, $\mathrm{Mg}_{2}\left(\mathrm{Si}_{0.3} \mathrm{Sn}_{0.7}\right)$ into its $\mathrm{Sn}$-rich and Si-rich conjugates. Therefore, we investigate the phase fractions when varying the $\mathrm{Si} / \mathrm{Sn}$ composition ratio in the $\mathrm{TE}$ material in Fig. 9. The selected compositions 40/60 and 50/50 are known to have good thermoelectric properties as well as $30 / 70$, and $70 / 30$ was chosen for completeness. When the Si content in the TE material increases, we can observe in the 1st column that $\mathrm{C} 15$ exists in a narrower $\mathrm{Cu}$ composition range towards Cu-rich, C15 shows less $\mathrm{Cu}$ content depletion (2nd column), increases the amount and range of existence of $\tau_{1^{-}}$ $\mathrm{Cu}_{3} \mathrm{Mg}_{2} \mathrm{Si}$, there is an interplay between $\mathrm{C} 1 \mathrm{Mg}_{2} \mathrm{X}^{\prime}$ Sn-rich (C1\#1) and C1_ $\mathrm{Mg}_{2} \mathrm{X}^{\prime \prime}$ Si-rich (C1\#2) —where C1_ $\mathrm{Mg}_{2} \mathrm{X}^{\prime}$ forms at higher $\mathrm{Cu}$ compositions in the four cases but its fraction decreases while C1_ $\mathrm{Mg}_{2} \mathrm{X}^{\prime \prime}$ fraction increases-, the fraction of $\tau_{2}-\mathrm{Cu}_{4} \mathrm{MgSn}$ decreases, bcc_A2 stabilizes in case $d$, the liquid fraction slightly increases and it is stable in a broader $\mathrm{Cu}$ composition range.

The types of diagrams presented in Fig. 9 are an extremely useful tool for direct comparison with chemical analyses for phase identification in complex microstructures. In addition, they are important for the interpretation of phase transformations and possible growth-kinetic mechanisms as shown for the case of $\mathrm{Mg}_{2}\left(\mathrm{Si}_{x} \mathrm{Sn}_{1-x}\right) / \mathrm{Cu}$ contacts.

These diagrams were also used here to show the significant amount of information that can be extracted from phase stability calculations.

4.2.2 The liquid phase in the contacting process. The liquid phase was selected in the previous section together with the C15 and C1_Mg2X phases to calculate its fraction and elemental distribution. The composition of the liquid is of particular interest due to the consequences on diffusion and segregation that the presence of a liquid in the IZ can bring about. A liquid phase accelerates diffusion and acts as a wetting agent, and these features are not necessarily undesired but should be carefully considered. In the present system, the liquid phase can be present in the consolidation stage of the mechanically alloyed powders (synthesis of the pellets) and also in the contacting stage, most likely, for different reasons. In the former, the probability of $\mathrm{Mg}$ evaporation from the pellets is high at $700{ }^{\circ} \mathrm{C}$ and therefore the $\mathrm{Mg}$ composition in the pellet can easily show Mg-rich and poor regions around the stoichiometric composition of 66.67 at $\% \mathrm{Mg}$ (see Fig. 1 in the ESI $\dagger$ ). In the latter, although at lower temperature, $600{ }^{\circ} \mathrm{C}$, the local variations in composition may result from the diffusion of melting point depressant elements into the TE material to form, for example, a ternary or quaternary eutectic. The effects of stabilizing a particular phase can be desired or not, and in either case phase diagrams can be used to identify the operating conditions for the targeted phases.

The calculated vertical section from $\mathrm{Mg}_{2}\left(\mathrm{Si}_{0.3} \mathrm{Sn}_{0.7}\right)$ to pure $\mathrm{Cu}$ as a function of temperature in Fig. 10 shows regions in the temperature-composition space, where the indicated phases are in equilibrium. The blue line indicates the zero phase fraction (ZPF) for the liquid and the blue area indicates all thermodynamic states where liquid exists. Similarly, the ZPF is indicated for the TE material, phase $\mathrm{C}_{-} \mathrm{Mg}_{2} \mathrm{X}$ with the two composition sets $\mathrm{C} 1 \# 1$ and $\mathrm{C} 1 \# 2$, in red. From the intersection of the red and 


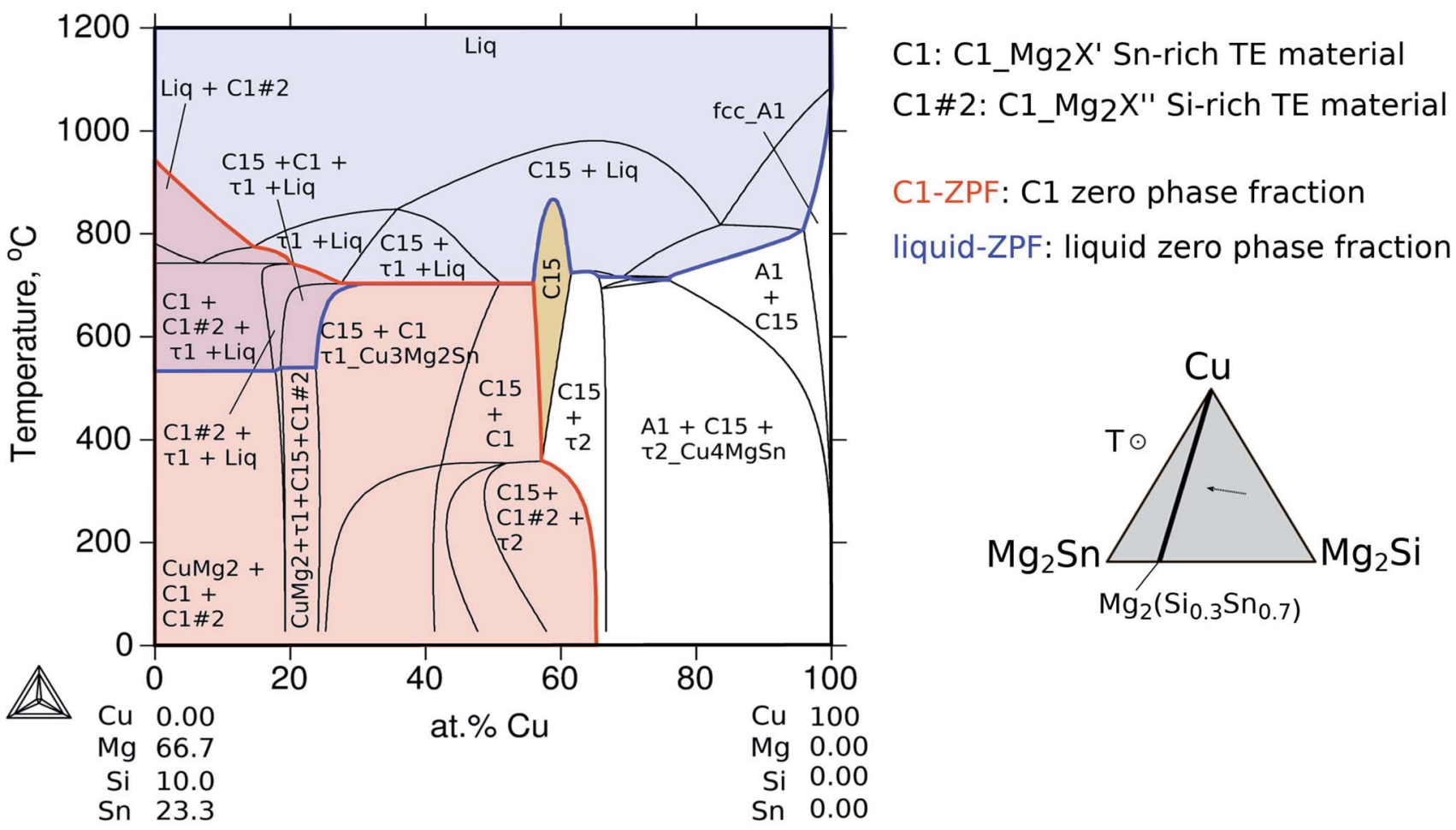

Fig. 10 Calculated vertical section from $\mathrm{Mg}_{2}\left(\mathrm{Si}_{0.3} \mathrm{Sn}_{0.7}\right)$ to pure Cu versus temperature to indicate the curves of the zero phase fraction for two phases of interest, the liquid (blue) and C1\#1 and C1\#2 (orange).

blue areas, the thermodynamic states for the coexistence of the two phases can be determined.

This type of diagram is particularly useful to optimize synthesis and contacting conditions to obtain the right phase or phase sequence. The liquid ZPF line indicates the limit of the liquid appearance as a function of $\mathrm{Cu}$ composition. For the present investigation, it clearly shows that at the contacting temperature $600{ }^{\circ} \mathrm{C}$ the liquid phase was present resulting in successful interconnections, whereas, at temperatures below the liquid ZPF there is no liquid and therefore for the same contacting time the bonding is not expected to be so effective as the diffusion-reaction process must occur in the solid state. This is in agreement with the experimental results from Ayachi et al. ${ }^{10}$ where it was observed that a successful joining/bonding was possible at $600{ }^{\circ} \mathrm{C}$, but failed at $500{ }^{\circ} \mathrm{C}$.

4.2.3 Possible diffusion path and growth sequence scheme. The diffusion path can be drawn on a phase diagram and it is a line representing the locus of average composition; in the case of a diffusion couple, it is the average composition measured in planes parallel to the original interface throughout the diffusion zone. ${ }^{\mathbf{4 1}}$ Therefore the diffusion path determination requires monitoring the composition in the IZ at several stages of the diffusion-reaction process. Based only on the inspection of the final microstructure and thermodynamic information the diffusion path can't be determined, but some hints given in Section 4.2.1 lead us to outline a possible path in Fig. 11. The blue square is the composition of the bulk TE leg $\mathrm{Mg}_{2}\left(\mathrm{Si}_{0.3} \mathrm{Sn}_{0.7}\right)$ and the black dots are the measured average composition in layers assigned to $\mathrm{C} 15$ and $\tau_{1}-\mathrm{Cu}_{3} \mathrm{Mg}_{2} \mathrm{Si}$ after contacting. The dotted lines linking C1_ $\mathrm{Mg}_{2} \mathrm{Sn}$ and $\mathrm{C} 1 \_\mathrm{Mg}_{2} \mathrm{Si}$ with $\mathrm{Cu}$ represent the sides of the section in Fig. 8a, while the blue full lines indicate a possible diffusion path followed by the $\mathrm{TE} / \mathrm{Cu}$ couple during $10 \mathrm{~min}$ at $600{ }^{\circ} \mathrm{C}$ in the sinter press.

On the $\mathrm{Cu}-\mathrm{Mg}-\mathrm{Sn}$ diagram the diffusion path can follow tielines in the 2-phase field, $(\mathrm{Cu})+\mathrm{C} 15$ _ $\mathrm{Cu}_{2} \mathrm{MgSn}$, deviating from the analysed section (dotted black lines) and avoiding the formation of $\tau_{2}-\mathrm{Cu}_{4} \mathrm{MgSn}$. The final state in the IZ indicates experimentally 3-phase equilibria: $\mathrm{C} 1 \mathrm{Mg}_{2} \mathrm{X}^{\prime}+\tau_{1}-\mathrm{Cu}_{3} \mathrm{Mg}_{2} \mathrm{Si}+$ $\mathrm{C} 15$ in agreement with the phase diagram. The black dot in the $\mathrm{Cu}-\mathrm{Mg}$-Si ternary, Fig. 11, is near the limit of a 3-phase field with the Mg-rich liquid that might be present in the IZ and responsible for the roundish morphology of $\tau_{1}-\mathrm{Cu}_{3} \mathrm{Mg}_{2} \mathrm{Si}$ precipitates. It is worth noticing from the diagram that any local variation in $\mathrm{Mg}$ composition, both enriched or deficient, can deviate the diffusion path from the analysed plane $\left(\mathrm{Mg}_{2} \mathrm{Sn}-\right.$ $\mathrm{Mg}_{2} \mathrm{Si}-\mathrm{Cu}$ ) leading to the formation of a $\mathrm{Mg}$-rich liquid or $\mathrm{Sn}$ rich liquid.

Finally, the growth sequence of the interlayers can be seen in a scheme in Fig. 12. A plausible initial situation at $t_{0}$ is the formation of the solid solution $(\mathrm{Cu})$ until saturation leading to the formation of $\mathrm{C} 15 \_\mathrm{Cu}_{2} \mathrm{MgSn}$ dissolving $\sim 4$ at\% of Si that is C15 quaternary extension at $t_{1}$. Subsequently, C15 can equilibrate with C1_ $\mathrm{Mg}_{2} \mathrm{Sn}$ at $t_{2}$ and, eventually, $\tau_{1}-\mathrm{Cu}_{3} \mathrm{Mg}_{2} \mathrm{Si}$ nucleates at the interface $\mathrm{Mg}_{2}\left(\mathrm{Si}_{0.3} \mathrm{Si}_{0.7}\right) / \mathrm{C} 1 \_\mathrm{Mg}_{2} \mathrm{Sn}\left(t_{3}\right)$. Probably, after or simultaneously the liquid phase can form (by $\mathrm{Si}$ depletion in the TE material and/or Mg-depleted regions in the $\mathrm{C} 1$ layer) and shape the precipitates of $\tau_{1}-\mathrm{Cu}_{3} \mathrm{Mg}_{2} \mathrm{Si}$. 


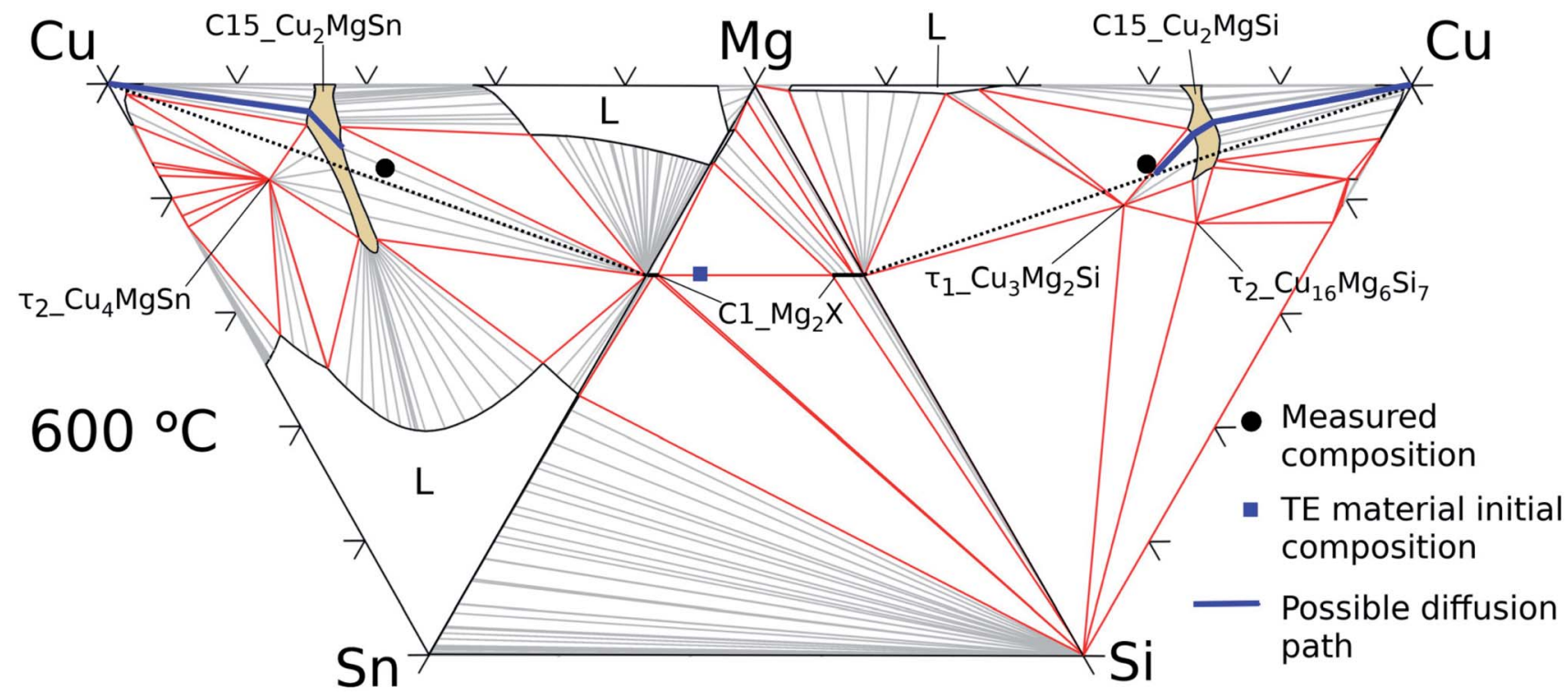

Fig. $11 \mathrm{Cu}-\mathrm{Mg}-\mathrm{Si}, \mathrm{Mg}-\mathrm{Si}-\mathrm{Sn}$, and $\mathrm{Cu}-\mathrm{Mg}-\mathrm{Sn}$ isothermal sections at $600^{\circ} \mathrm{C}$ with average measured composition in the interconnection zone (black circles) and in the thermoelectric material (blue square).

4.2.4 Thermodynamic consideration of dopant elements. The dopant elements have an important effect on the transport properties of the TE elements. However, since the objective of this work is to investigate the phase transformations leading to a multilayered microstructure in the IZ the dopants $\mathrm{Bi}$ and $\mathrm{Li}$ were not included in the present thermodynamic description. The elements $\mathrm{Bi}$ and $\mathrm{Li}$ in dopant concentrations do not affect the global phase equilibria, and it is safe to assume that they do not significantly modify the free energy of the solid phases. No phases related to Bi or Li systems have been identified in the IZ; therefore, the solubility limits of $\mathrm{Bi}$ and $\mathrm{Li}$ in the observed phases in the IZ have not been exceeded. Below the solubility limit, the dopant species are dissolved in the crystal structure of the given phase. In fact, the composition of Bi measured in the samples of about 2.6 at\% was always in the $\mathrm{C}_{-} \_\mathrm{Mg}_{2} \mathrm{Sn}$ phase. Although dopants don't have a significant effect on the thermodynamic stability of the phases in this system, they certainly have a strong influence on their defect structure.

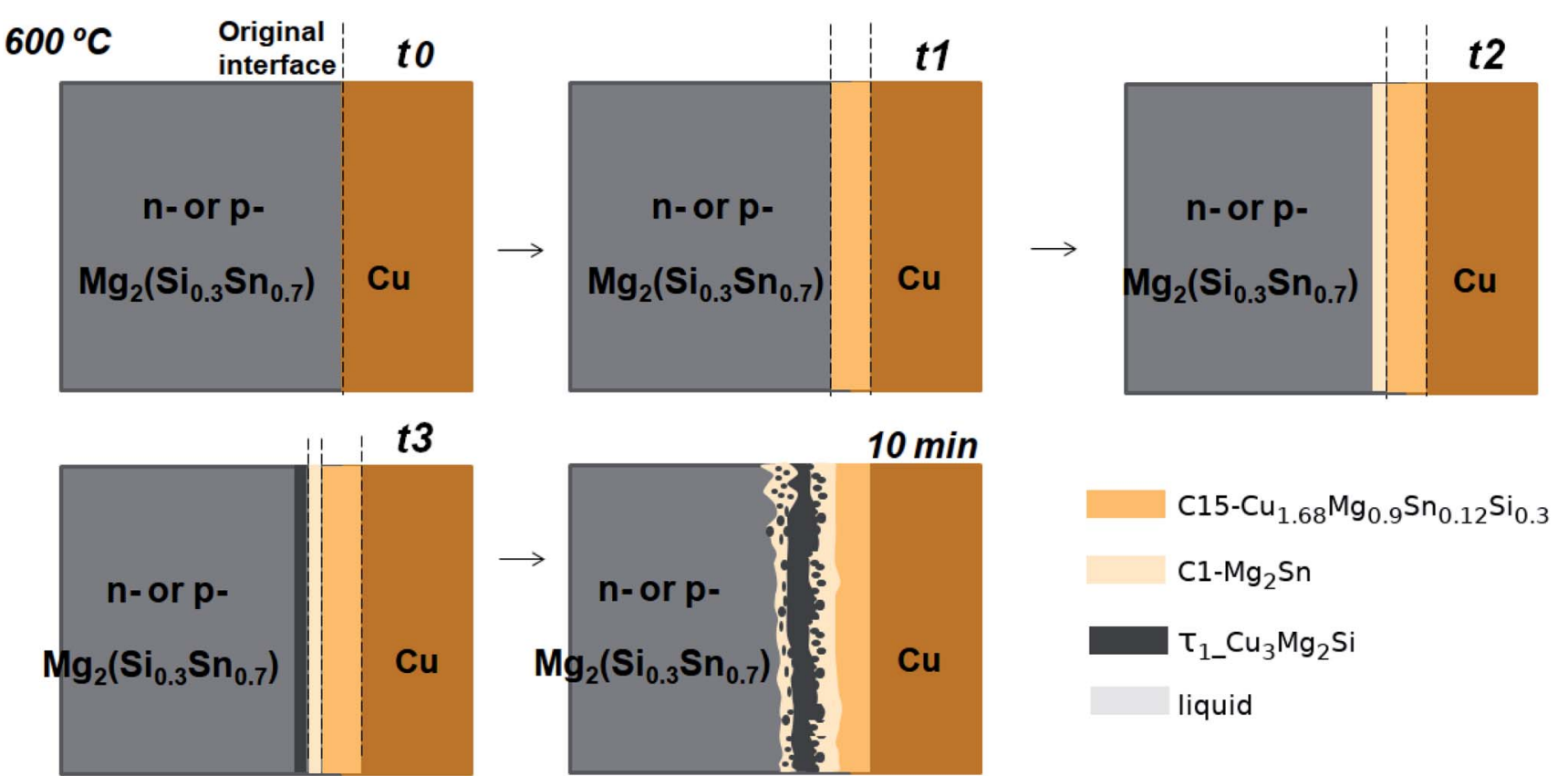

Fig. 12 Scheme of a possible growing sequence of intermediate layers in $\mathrm{Mg}_{2}\left(\mathrm{Si}_{0}{ }_{3} \mathrm{Sn}_{0.7}\right) / \mathrm{Cu}$ interconnections produced in a sinter press for $10 \mathrm{~min}$ at $600^{\circ} \mathrm{C}$. 
Table 2 Parameters used in this work (tw), given in $\mathrm{J} \mathrm{mol}^{-1}$. With reference to the species, 1: $\mathrm{Cu}, 2: \mathrm{Mg}, 3: \mathrm{Mg}_{2} \mathrm{Sn}, 4: \mathrm{Si}$ and 5: Sn

\begin{tabular}{|c|c|c|c|c|c|c|c|c|c|}
\hline Phase & Eqn & $i-j, \nu$ & $a, a_{\boldsymbol{v}}, \boldsymbol{a}_{\boldsymbol{i}-\boldsymbol{j}}$ & $b, b_{\boldsymbol{\nu}}, \boldsymbol{b}_{\boldsymbol{i}-\boldsymbol{j}}$ & $c, c_{\nu}$ & $d 10^{4}$ & $e$ & $f 10^{6}$ & Ref. \\
\hline \multirow[t]{19}{*}{ C15 } & $(2)$ & $1: 1$ & 15000 & & & & & & 33 \\
\hline & & $2: 2$ & 15000 & & & & & & 33 \\
\hline & & $5: 5$ & 15000 & & & & & & Tw \\
\hline & & $1: 2$ & -54690.99 & 364.73085 & -69.27642 & -5.19246 & 143502 & -5.65953 & 33 \\
\hline & & $2: 1$ & 104971 & -16.4645 & & & & & 33 \\
\hline & & $1: 1-2$ & 6599.45 & & & & & & 33 \\
\hline & & $2: 1-2$ & 6599.45 & & & & & & 33 \\
\hline & & $4: 1$ & 90000 & & & & & & 33 \\
\hline & & $1: 4$ & 90000 & & & & & & 33 \\
\hline & & $2: 4$ & 90000 & & & & & & 33 \\
\hline & & $4: 2$ & 90000 & & & & & & 33 \\
\hline & & $2: 5$ & 0.0 & & & & & & 37 \\
\hline & & $5: 2$ & 0.0 & & & & & & 37 \\
\hline & & $2-5: 5$ & 15000 & & & & & & 33 \\
\hline & & $2-5: 2$ & 15000 & & & & & & 33 \\
\hline & & $1: 5$ & 90000 & & & & & & Tw \\
\hline & & $5: 1$ & 90000 & & & & & & Tw \\
\hline & & $1-5: 2$ & -102000 & 5 & & & & & Tw \\
\hline & & $1: 2-5$ & -189000 & & & & & & Tw \\
\hline \multirow[t]{4}{*}{ fcc } & (3) & $1-2,0$ & -22059.61 & 5.63232 & & & & & 30 \\
\hline & & $1-4,0$ & -42203.5 & 13.89137 & & & & & 32 \\
\hline & & $1-4,1$ & -1102.2 & -18.177912 & & & & & 32 \\
\hline & & $1-5,0$ & -12912 & 4.72 & & & & & 31 \\
\hline \multirow[t]{6}{*}{ hep } & (3) & $2-5,0$ & -30000 & -3 & & & & & 26 \\
\hline & & $2-5,1$ & -11293.8 & -4.42051 & & & & & 26 \\
\hline & & $2-4,0$ & -7148.79 & 0.894 & & & & & 20 \\
\hline & & $1-2,0$ & +22500 & -3 & & & & & 30 \\
\hline & & $1-4,0$ & -26798.8 & -0.731518 & & & & & 32 \\
\hline & & $1-4,1$ & -28064.75 & -0.028889 & & & & & 32 \\
\hline bct & (3) & $1-5,0$ & 21000 & & & & & & 45 \\
\hline diamond & (3) & $4-5,0$ & 25265.65 & 23.84 & & & & & 20 \\
\hline \multirow[t]{4}{*}{$\mathrm{Mg}_{2} \mathrm{X}$} & (2) & $2: 4$ & -16177.5 & 3.8967 & & & & & 18 \\
\hline & & $2: 5$ & -31024.2 & 110.918 & -21.8911 & -0.003028 & -210000 & & 26 \\
\hline & & $2: 4-5,0$ & 5000 & & & & & & 17 \\
\hline & & $2: 4-5,1$ & -900 & & & & & & 17 \\
\hline $\mathrm{Cu}_{4} \mathrm{MgSn}$ & (1) & & -19600 & 5 & & & & & 37 \\
\hline CuMgSn & (1) & & -26500 & 10 & & & & & 37 \\
\hline $\mathrm{Cu}_{16} \mathrm{Mg}_{6} \mathrm{Si}_{7}$ & (1) & & 506236 & 20.0884 & & & & & 33 \\
\hline CuMgSi & (1) & & -129354 & 8.43518 & & & & & 33 \\
\hline \multirow[t]{3}{*}{$\mathrm{Cu}_{15} \mathrm{Si}_{4}$} & (2) & $1: 4$ & 1240.9639 & -6.7191165 & & & & & 33 \\
\hline & & $2: 4$ & 5000 & & & & & & 33 \\
\hline & & $1-2: 4$ & -40000 & 25 & & & & & 33 \\
\hline \multirow[t]{3}{*}{$\mathrm{Cu}_{56} \mathrm{Si}_{11}$} & $(2)$ & $1: 4$ & 1046.4873 & -5.8746832 & & & & & 33 \\
\hline & & $2: 4$ & 5000 & & & & & & 33 \\
\hline & & $1-2: 4$ & -37000 & 3 & & & & & 33 \\
\hline $\mathrm{Cu}_{19} \mathrm{Si}_{6}$ & (1) & & 1367.66222 & -7.1976229 & & & & & 32 \\
\hline $\mathrm{Cu}_{33} \mathrm{Si}_{7}$ & (1) & & 1972.382 & -6.9663933 & & & & & 32 \\
\hline $\mathrm{Cu}_{41} \mathrm{Sn}_{11}$ & (1) & & -6323.5 & -1.2808 & & & & & 31 \\
\hline
\end{tabular}


Table 2 (Contd.)

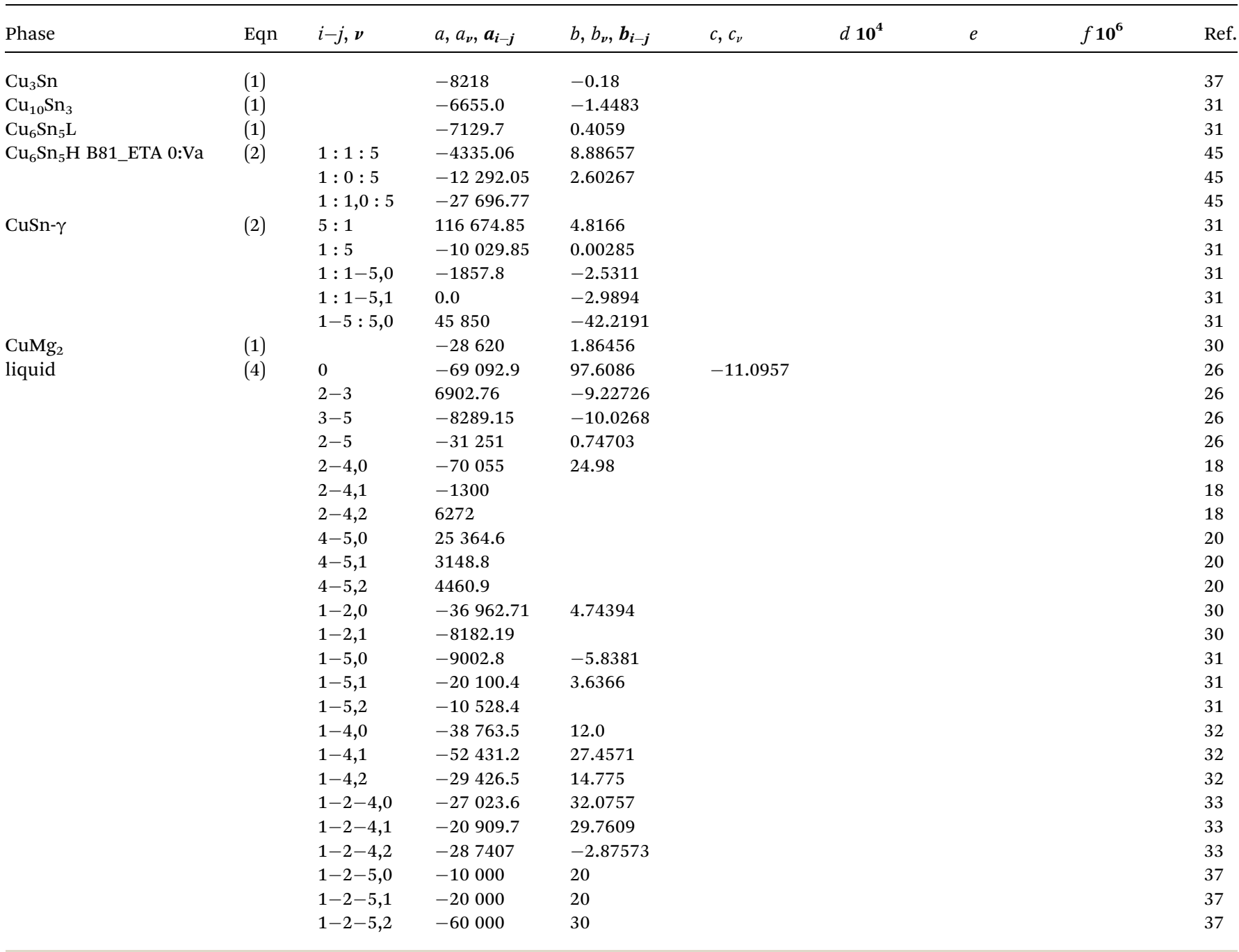

Nevertheless, the present thermodynamic description can be enlarged to account for dopant elements, charged carriers, ${ }^{\mathbf{4 3 , 4 4}}$ coating elements and more complex point defect structures. In the present thermodynamic database, only substitutional defects are allowed, yet it represents a significant starting point for incremental improvements based on the proposed ground thermodynamic description. This description was already effective to understand the contacts in this study.

\section{Conclusions}

In this case study, a two step contacting route using $\mathrm{Cu}$ as a noncomplex electrode was selected to show significant results derived only from equilibrium calculations. We provided an open access set of Gibbs energies for all the phases in the quaternary $\mathrm{Cu}-\mathrm{Mg}-\mathrm{Si}-\mathrm{Sn}$ system, and with this tool we calculated several diagrams and applied them to the investigation of $\mathrm{Mg}_{2}\left(\mathrm{Si}_{0.3} \mathrm{Sn}_{0.7}\right) / \mathrm{Cu}$ contacts. The thermodynamic calculations contributed significantly:
- To effectively anticipate the constitution (crystal structure of the phases and composition) of the intermediate layers formed in the interconnection zone of $\mathrm{Mg}_{2}\left(\mathrm{Si}_{0.3} \mathrm{Sn}_{0.7}\right) / \mathrm{Cu}$ junctions.

- By providing the phase amount and composition diagrams for in situ comparison with chemical analysis.

- In the interpretation of the microstructure and morphology in the reacted interconnection zone allowing the outlining of a possible growth sequence for the intermediate layers combined with minimum experimental work.

- In providing phase diagrams and thermochemical property diagrams to support knowledge on phase transformations and kinetics.

- In providing a roadmap for the identification of processing conditions to grow desired phases or microstructures. This allows the determination of suitable contacting parameters for the manufacture of efficient TE material/metal interconnections using the knowledge on the liquid zero phase fraction, thus making this fundamental approach extremely useful in practice. 
The approach here used can be extended by enlarging the thermodynamic description to more complex electrodes and different types of coatings, while coupled to kinetics to describe further properties of the contacts and the TE material itself.

The assembled set of Gibbs energies meets the needs of a thermodynamic database for joining processes contributing with reliable thermodynamic descriptions in a broad range of composition and temperature, i.e. in the whole $\mathrm{Cu}$ composition space, and therefore the open set of Gibbs energies in this work is a crucial starting point for computational materials/processing design and certainly for further contributions. Hence, the first steps for accelerating the development of contact solutions for thermoelectric materials and improving the TEG fabrication process were presented in this work.

\section{Appendix A: thermodynamic formalism}

Several symbols will be used in this section, defined as follows: i, species. With $\mathrm{i}=\mathrm{Cu}, \mathrm{Mg}, \mathrm{Mg}_{2} \mathrm{Sn}, \mathrm{Si}, \mathrm{Sn}$.

$x_{\mathrm{i}}$, mole fraction of species $\mathrm{i}$.

$y_{i}^{\prime}$ and $y^{\prime \prime}{ }_{i}$, site fraction of species $i$ in the first and second sublattices.

$v$, set of integers in the Redlich-Kister power series.

1: $\mathrm{Cu}, 2: \mathrm{Mg}, 3: \mathrm{Mg}_{2} \mathrm{Sn}, 4: \mathrm{Si}$ and 5: $\mathrm{Sn}$, as coefficient's subindices.

Boldface means the major species in a given sublattice.

Stoichiometric compounds

$$
G-H^{\mathrm{SER}}=a+b T+c T \ln T+\mathrm{d} T^{2}+e T^{-1}+f T^{3}
$$

\subsection{C15: sublattice model}

$(\mathbf{C u}, \mathrm{Mg}, \mathrm{Si}, \mathrm{Sn})_{2}(\mathrm{Cu}, \mathbf{M g}, \mathrm{Si}, \mathrm{Sn})_{1}$

with

$$
{ }^{v} L_{i-j: k}^{\mathrm{C} 15}=a_{i-j: k}{ }^{\nu}+b_{i-j: k}{ }^{\nu} T
$$

where $L_{i-j: k}^{\mathrm{C} 15}$ means the interaction parameter between species $i$ and $j$ when species $k$ is in the second sublattice.

Solid solutions: Redlich-Kister formalism

$$
\begin{gathered}
G^{\phi}=\sum_{i=1}^{n} x_{i}^{\circ} G_{i}^{\phi}+R T \sum_{i=1}^{n} x_{i} \ln \left(x_{i}\right) \\
+x_{\mathrm{Cu}} x_{\mathrm{Mg}} \sum_{\nu=0}\left(a_{1-2^{\nu}}+b_{1-2}{ }^{\nu}\right)\left(x_{\mathrm{Cu}}-x_{\mathrm{Mg}}\right)^{\nu} \\
+x_{\mathrm{Cu}} x_{\mathrm{Si}} \sum_{\nu=0}\left(a_{1-4}{ }^{\nu}+b_{1-4}{ }^{\nu}\right)\left(x_{\mathrm{Cu}}-x_{\mathrm{Si}}\right)^{\nu} \\
+x_{\mathrm{Cu}} x_{\mathrm{Sn}} \sum_{\nu=0}\left(a_{1-5}{ }^{\nu}+b_{1-5}{ }^{\nu}\right)\left(x_{\mathrm{Cu}}-x_{\mathrm{Sn}}\right)^{\nu} \\
+x_{\mathrm{Mg}} x_{\mathrm{Sn}} \sum_{\nu=0}\left(a_{2-5}{ }^{\nu}+b_{2-5}{ }^{\nu}\right)\left(x_{\mathrm{Mg}}-x_{\mathrm{Sn}}\right)^{\nu} \\
+x_{\mathrm{Mg}} x_{\mathrm{Si}} \sum_{\nu=0}\left(a_{2-4}{ }^{\nu}+b_{2-4}{ }^{\nu}\right)\left(x_{\mathrm{Mg}}-x_{\mathrm{Si}}\right)^{\nu} \\
+x_{\mathrm{Si}} x_{\mathrm{Sn}} \sum_{\nu=0}\left(a_{4-5}{ }^{\nu}+b_{4-5}{ }^{\nu}\right)\left(x_{\mathrm{Si}}-x_{\mathrm{Sn}}\right)^{\nu}
\end{gathered}
$$

\section{Liquid phase: associate-solution model}

The associate species is $\mathrm{Mg}_{2} \mathrm{Sn}$ as a constituent of the liquid phase. This model uses site fractions $y_{i}$, as previously defined, to emphasize that the fraction of constituents is not the same as the component mole fractions, and then it follows:

$$
n=y_{\mathrm{Cu}}+y_{\mathrm{Mg}}+3 y_{\mathrm{Mg}_{2} \mathrm{Sn}}+y_{\mathrm{Si}}+y_{\mathrm{Sn}}
$$

where $n$ is the number of moles of atoms in $1 \mathrm{~mol}$ of species.

where $a$ to $f$ are coefficients.

$$
\begin{aligned}
& G^{\mathrm{C} 15}-H^{\mathrm{SER}}=y_{\mathrm{Cu}}^{\prime} y^{\prime \prime}{ }_{\mathrm{Cu}}^{\circ} G_{\mathrm{Cu}: \mathrm{Cu}}^{\mathrm{C} 15}+y_{\mathrm{Mg}}^{\prime} y_{\mathrm{Mg}}^{\prime \prime} G_{\mathrm{Mg}: \mathrm{Mg}}^{\mathrm{C} 15}+y_{\mathrm{Si}}^{\prime} y_{\mathrm{Si}}^{\prime \prime} G_{\mathrm{Si}: \mathrm{Si}}^{\mathrm{C} 15}+y_{\mathrm{Sn}}^{\prime} y_{\mathrm{Sn}}^{\prime \prime} G_{\mathrm{Sn}: \mathrm{Sn}}^{\mathrm{C} 15} \\
& +y_{\mathrm{Cu}}^{\prime} y^{\prime \prime}{ }_{\mathrm{Mg}}^{\circ} G_{\mathrm{Cu}: \mathrm{Mg}}^{\mathrm{C} 15}+y_{\mathrm{Cu}}^{\prime} y_{\mathrm{Si}}^{\prime \prime} G_{\mathrm{Cu}: \mathrm{Si}}^{\mathrm{Cl}}+y_{\mathrm{Cu}}^{\prime} y_{\mathrm{Sn}}^{\prime \prime} G_{\mathrm{Cu}: \mathrm{Sn}}^{\mathrm{Cl}}+y_{\mathrm{Mg}}^{\prime} y^{\prime \prime}{ }_{\mathrm{Cu}}^{\circ} G_{\mathrm{Mg}: \mathrm{Cu}}^{\mathrm{Cl} 15} \\
& +y_{\mathrm{Mg}}^{\prime} y^{\prime \prime}{ }_{\mathrm{Si}}^{\circ} G_{\mathrm{Mg}: \mathrm{Si}}^{\mathrm{Cl} 5}+y_{\mathrm{Mg}}^{\prime} y_{\mathrm{Sn}}{ }^{\circ} G_{\mathrm{Mg}: \mathrm{Sn}}^{\mathrm{Cl} 15}+y_{\mathrm{Si}}^{\prime} y^{\prime \prime}{ }_{\mathrm{Cu}}{ }^{\circ} G_{\mathrm{Si}: \mathrm{Cu}}^{\mathrm{Cl}}+y_{\mathrm{Si}}^{\prime} y^{\prime \prime}{ }_{\mathrm{Mg}}{ }^{\circ} G_{\mathrm{Si}: \mathrm{Mg}}^{\mathrm{Cl} 5} \\
& +y_{\mathrm{Si}}^{\prime} y^{\prime \prime}{ }_{\mathrm{Sn}}^{\circ} G_{\mathrm{Si}: \mathrm{Sn}}^{\mathrm{C} 15}+y_{\mathrm{Sn}}^{\prime} y^{\prime \prime}{ }_{\mathrm{Cu}}^{\circ} G_{\mathrm{Sn}: \mathrm{Cu}}^{\mathrm{C} 15}+y_{\mathrm{Sn}}^{\prime} y^{\prime \prime}{ }_{\mathrm{Mg}}^{\circ} G_{\mathrm{Sn}: \mathrm{Mg}}^{\mathrm{C} 15}+y_{\mathrm{Sn}}^{\prime} y_{\mathrm{Si}}^{\prime \prime} G_{\mathrm{Sn}: \mathrm{Si}}^{\mathrm{C} 15} \\
& +2 R T \sum_{\mathrm{i}=\mathrm{Cu}, \mathrm{Mg}, \mathrm{Si}, \mathrm{Sn}}^{n} y_{\mathrm{i}}^{\prime} \ln \left(y_{\mathrm{i}}^{\prime}\right)+R T \sum_{\mathrm{i}=\mathrm{Cu}, \mathrm{Mg}, \mathrm{Si}, \mathrm{Sn}}^{n} y_{\mathrm{i}}^{\prime \prime} \ln \left(y_{\mathrm{i}}^{\prime \prime}\right) \\
& +y_{\mathrm{Cu}}^{\prime} y_{\mathrm{Mg}}^{\prime}\left(y^{\prime \prime}{ }_{\mathrm{Cu}} L_{\mathrm{Cu}, \mathrm{Mg}: \mathrm{Cu}}^{\mathrm{C} 15}+y^{\prime \prime}{ }_{\mathrm{Mg}} L_{\mathrm{Cu}, \mathrm{Mg}: \mathrm{Mg}}^{\mathrm{C} 15}\right) \\
& +y^{\prime \prime}{ }_{\mathrm{Cu}} y^{\prime \prime}{ }_{\mathrm{Mg}}\left(y_{\mathrm{Cu}}^{\prime} L_{\mathrm{Cu}: \mathrm{Cu}, \mathrm{Mg}}^{\mathrm{C} 15}+y_{\mathrm{Mg}}^{\prime} L_{\mathrm{Mg}: \mathrm{Cu}, \mathrm{Mg}}^{\mathrm{C} 15}\right) \\
& +y_{\mathrm{Mg}}^{\prime} y_{\mathrm{Si}}^{\prime}\left(y^{\prime \prime}{ }_{\mathrm{Mg}} L_{\mathrm{Mg}, \mathrm{Si}: \mathrm{Mg}}^{\mathrm{C} 15}+y_{\mathrm{Si}}^{\prime \prime} L_{\mathrm{Mg}, \mathrm{Si}: \mathrm{Si}}^{\mathrm{C} 15}\right)+y^{\prime \prime}{ }_{\mathrm{Mg}} y_{\mathrm{Si}}^{\prime \prime}\left(y_{\mathrm{Cu}}^{\prime} L_{\mathrm{Cu}: \mathrm{Mg}, \mathrm{Si}}^{\mathrm{C} 15}\right) \\
& +y_{\mathrm{Mg}}^{\prime} y_{\mathrm{Sn}}^{\prime}\left(y^{\prime \prime}{ }_{\mathrm{Sn}} L_{\mathrm{Mg}, \mathrm{Sn}: \mathrm{Sn}}^{\mathrm{C} 15}+y^{\prime \prime}{ }_{\mathrm{Mg}} L_{\mathrm{Mg}, \mathrm{Sn}: \mathrm{Mg}}^{\mathrm{C} 15}\right)+y^{\prime \prime}{ }_{\mathrm{Mg}} y^{\prime \prime}{ }_{\mathrm{Sn}}\left(y_{\mathrm{Cu}}^{\prime} L_{\mathrm{Cu}: \mathrm{Mg}, \mathrm{Sn}}^{\mathrm{C} 15}\right) \\
& +y_{\mathrm{Cu}}^{\prime} y_{\mathrm{Si}}^{\prime}\left(y_{\mathrm{Mg}}^{\prime \prime} L_{\mathrm{Cu}, \mathrm{Si}: \mathrm{Mg}}^{\mathrm{C} 15}\right)+y_{\mathrm{Cu}}^{\prime} y_{\mathrm{Sn}}^{\prime}\left(y^{\prime \prime}{ }_{\mathrm{Mg}} L_{\mathrm{Cu}, \mathrm{Sn}: \mathrm{Mg}}^{\mathrm{C} 15}\right)
\end{aligned}
$$




$$
\begin{gathered}
G^{\mathrm{Liq}}=\sum_{i=1}^{n} x_{i}^{\circ} G_{i}^{\mathrm{Liq}}+R T / n\left[y_{\mathrm{Cu}} \ln \left(y_{\mathrm{Cu}}\right)+y_{\mathrm{Mg}} \ln \left(y_{\mathrm{Mg}}\right)+y_{\mathrm{Mg}_{2} \mathrm{Sn}} \ln \left(y_{\mathrm{Mg}_{2} \mathrm{Sn}}\right)+y_{\mathrm{Si}} \ln \left(y_{\mathrm{Si}}\right) y_{\mathrm{Sn}} \ln \left(y_{\mathrm{Sn}}\right)\right] \\
+y_{\mathrm{Mg}_{2} \mathrm{Sn}}\left(a_{0}+b_{0} T+c_{0} T \ln T\right) / n \\
+y_{\mathrm{Mg}} y_{\mathrm{Mg}_{2} \mathrm{Sn}}\left(a_{2-3}+b_{2-3} T\right) / n \\
+y_{\mathrm{Mg}} y_{\mathrm{Sn}}\left(a_{2-5}+b_{2-5} T\right) / n \\
+y_{\mathrm{Mg}} y_{\mathrm{Mg} 2 \mathrm{Sn}}\left(a_{3-5}+b_{3-5} T\right) / n \\
+\sum_{\nu} y_{\mathrm{Mg}} y_{\mathrm{Si}}\left(y_{\mathrm{Mg}}-y_{\mathrm{Si}}\right)^{\nu}\left(a_{2-4}{ }^{\nu}+b_{2-4}{ }^{\nu} T\right) / n \\
+\sum_{\nu} y_{\mathrm{Si}} y_{\mathrm{Sn}}\left(y_{\mathrm{Si}}-y_{\mathrm{Sn}}\right)^{\nu}\left(a_{4-5}{ }^{\nu}+b_{4-5}{ }^{\nu} T\right) / n \\
+\sum_{\nu} y_{\mathrm{Cu}} y_{\mathrm{Mg}}\left(y_{\mathrm{Cu}}-y_{\mathrm{Mg}}\right)^{\nu}\left(a_{1-2}{ }^{\nu}+b_{1-2}{ }^{\nu} T\right) / n \\
+\sum_{\nu} y_{\mathrm{Cu}} y_{\mathrm{Sn}}\left(y_{\mathrm{Mg}}-y_{\mathrm{Sn}}\right)^{\nu}\left(a_{1-5}{ }^{\nu}+b_{1-5}{ }^{\nu} T\right) / n \\
+\sum_{\nu} y_{\mathrm{Cu}} y_{\mathrm{Si}}\left(y_{\mathrm{Cu}}-y_{\mathrm{Si}}\right)^{\nu}\left(a_{1-4}{ }^{\nu}+b_{1-4}{ }^{\nu} T\right) / n \\
+y_{\mathrm{Cu}} y_{\mathrm{Mg}} y_{\mathrm{Si}}\left[\left(a_{1-2-4}{ }^{0}+b_{1-2-4}{ }^{0} T\right) y_{\mathrm{Cu}}+\left(a_{1-2-4}{ }^{1}+b_{1-2-4}{ }^{1} T\right) y_{\mathrm{Mg}}+\left(a_{1-2-4}{ }^{2}+b_{1-2-4}{ }^{2} T\right) y_{\mathrm{Si}}\right] \\
+y_{\mathrm{Cu}} y_{\mathrm{Mg}} y_{\mathrm{Sn}}\left[\left(a_{1-2-5}{ }^{0}+b_{1-2-5}{ }^{0} T\right) y_{\mathrm{Cu}}+\left(a_{1-2-5}{ }^{1}+b_{1-2-5}{ }^{1} T\right) y_{\mathrm{Mg}}+\left(a_{1-2-5}{ }^{2}+b_{1-2-5} T\right) y_{\mathrm{Sn}}\right]
\end{gathered}
$$

\section{Parameters used in this work}

Table 2.

\section{Author contributions}

All the authors contributed to writing, reviewing and editing. S. T. wrote the original draft of the manuscript, made the thermodynamic calculations, visualization, and did the formal analysis, data curation, validation, methodology and investigation; S. A. did all the experimental work, formal analysis, data curation, methodology and investigation; S. G. F. contributed to the conceptualization, software, validation and visualization; E. M. contributed to funding acquisition, resources, conceptualization, and supervision; J. d. B. was the project administrator, and did supervision, funding acquisition, and conceptualization. All authors have read and agreed to the published version of the manuscript.

\section{Conflicts of interest}

There are no conflicts to declare.

\section{Acknowledgements}

S. T. gratefully acknowledges the financial support of the Deutscher Akademischer Austauschdienst (DAAD) and the Deutsches Zentrum für Luft-und Raumfahrt (DLR, German Aerospace Center) through the DAAD-DLR fellowship program no. 314 and 57424730, and specially thanks Dr Ursula Kattner for providing Gibbs energies data related to $\mathrm{Cu}-\mathrm{Sn}$ binary phases, and Thermo-Calc AB for providing a temporary software license to facilitate the work remotely. J. d. B. and S. A. would like to gratefully acknowledge the endorsement from DLR Executive Board Members for Space Research and Technology and the financial support from the Young Research Group Leader Program. J. d. B. is also funded by the Deutsche Forschungsgemeinschaft (DFG, German Research Foundation), project number 396709363.

\section{References}

1 R. He, G. Schierning and K. Nielsch, Adv. Mater. Technol, 2018, 3, 1-17.

2 X.-L. Shi, J. Zou and Z.-G. Chen, Chem. Rev., 2020, 120, 73997515.

3 J. de Boor, T. Dasgupta, U. Saparamadu, E. Müller and Z. F. Ren, Mater. Today Energy, 2017, 4, 105-121.

4 H. Kamila, P. Sahu, A. Sankhla, M. Yasseri, N. H. Pham, T. Dasgupta, E. Müller and J. de Boor, J. Mater. Chem. A, 2019, 7, 1045-1054.

5 H. Kamila, A. Sankhla, M. Yasseri, N. Hoang, N. Farahi, E. Müller and J. de Boor, Mater. Today: Proc., 2019, 8, 546555.

6 V. K. Zaitsev, M. I. Fedorov, E. A. Gurieva, I. S. Eremin, P. P. Konstantinov, A. Y. Samunin and M. V. Vedernikov, $i k$ : Condens. Matter Mater. Phys., 2006, 74, 2-6.

7 W. Liu, X. Tan, K. Yin, H. Liu, X. Tang, J. Shi, Q. Zhang and C. Uher, Phys. Rev. Lett., 2012, 108, 1-5.

8 N. Farahi, C. Stiewe, D. Y. N. Truong, J. de Boor and E. Müller, $R S C$ Adv., 2019, 9, 23021-23028.

9 A. Sankhla, A. Patil, H. Kamila, M. Yasseri, N. Farahi, E. Müller and J. de Boor, ACS Appl. Energy Mater., 2018, 1, 531-542. 
10 S. Ayachi, G. Castillo Hernandez, N. H. Pham, N. Farahi, E. Müller and J. De Boor, ACS Appl. Mater. Interfaces, 2019, 11, 40769-40780.

11 X. Li, Z. Li, C. Chen, Z. Ren, C. Wang, X. Liu, Q. Zhang and S. Chen, J. Mater. Chem. A, 2021, 9, 6634-6649.

12 X. J. Liu, K. Oikawa, I. Ohnuma, R. Kainuma and K. Ishida, JOM, 2003, 55, 53-59.

13 S. Chen, Y. Chen, S. Ohno, L. Xu, W. Fan, L. Xue, M. Ferhat and Y. Wu, Phys. Status Solidi A, 2020, 217, 1901035.

14 B. Jayachandran, B. Prasanth, R. Gopalan, T. Dasgupta and D. Sivaprahasam, Mater. Res. Bull., 2021, 136, 111147.

15 H. Lukas, S. G. Fries and B. Sundman, Computational Thermodynamics. The Calphad Method, Cambridge University Press, 2007.

16 U. R. Kattner, JOM, 1997, 49, 14-19.

17 A. Kozlov, J. Gröbner and R. Schmid-Fetzer, J. Alloys Compd., 2011, 509, 3326-3337.

18 D. Kevorkov, R. Schmid-Fetzer and F. Zhang, J. Phase Equilib. Diffus., 2004, 25, 140-151.

19 B. C. Zhou, S. L. Shang and Z. K. Liu, CALPHAD: Comput. Coupling Phase Diagrams Thermochem., 2014, 46, 237-248.

20 I. Ansara, A. T. Dinsdale and M. H. Rand, COST 507 Thermochemical Database for Light Metals Alloys, Office for Official Publications of the European Communities, Luxemburg, 1998, p. 396.

21 S. Muntyanu, E. B. Sokolov and E. S. Makarov, Inorg. Mater., 1966, 2, 740-744.

22 E. N. Nikitin, E. N. Tkalenko, V. K. Zaitsev, A. Zaslavskii and A. K. Kuznetzov, Inorg. Mater., 1968, 4, 1656-1659.

23 I.-H. Jung, D.-H. Kang, W.-J. Park, N. J. Kim and S. Ahn, Calphad, 2007, 31, 192-200.

24 R. Orenstein, J. P. Male, M. Toriyama, S. Anand and G. J. Snyder, J. Mater. Chem. A, 2021, 9, 7208-7215.

25 M. Yasseri, K. Mitra, A. Sankhla, J. de Boor and E. Müller, Acta Mater., 2021, 208, 116737.

26 A. Kozlov, M. Ohno, R. Arroyave, Z. K. Liu and R. SchmidFetzer, Intermetallics, 2008, 16, 299-315.
27 TCSAB, Thermo-Calc Software AB, https://thermocalc.com/, accessed: 22 June 2021.

28 D. Kato, K. Iwasaki, M. Yoshino, T. Yamada and T. Nagasaki, Phys. Chem. Chem. Phys., 2018, 20, 25939-25950.

29 A. Sankhla, H. Kamila, K. Kelm, E. Müller and J. de Boor, Acta Mater., 2020, 199, 85-95.

30 C. A. Coughanowr, I. Ansara, R. Luoma, M. Hamalainen and H. L. Lukas, Z. Metallkd., 1991, 82, 574-581.

31 J.-H. Shim, C.-S. Oh, B.-J. Lee and D. N. Lee, Z. Metallkd., 1996, 87, 205-212.

32 X. Yan and Y. A. Chang, J. Alloys Compd., 2000, 308, 221-229.

33 J. Zhao, J. Zhou, S. Liu, Y. Du, S. Tang and Y. Yang, J. Min. Metall., Sect. B, 2016, 52, 99-112.

34 N. Bochvar, E. Lysova and L. Rokhlin, Landolt-Börnstein New Series IV/11A4, 2007, pp. 224-237.

35 E. E. Vicente, S. Bermudez, R. H. de Tendler, B. Arcondo and H. Sirkin, J. Mater. Sci. Lett., 1996, 15, 1690-1696.

36 B. Predel and H. Ruge, Mater. Sci. Eng., 1972, 9, 141-151.

37 J. Miettinen and G. Vassilev, J. Min. Metall., Sect. B, 2012, 48, 53-62.

38 S. I. Yi, V. Attari, M. Jeong, J. Jian, S. Xue, H. Wang, R. Arroyave and C. Yu, J. Mater. Chem. A, 2018, 6, 1755917570.

39 N. H. Pham, N. Farahi, H. Kamila, A. Sankhla, S. Ayachi, E. Müller and J. de Boor, Mater. Today Energy, 2019, 11, 97-105.

40 CRC Handbook of Chemistry and Physics, ed. R. C. Weast, CRC Press, USA, 55th edn, 1974.

41 A. A. Kodentsov, G. F. Bastin and F. J. Van Loo, J. Alloys Compd., 2001, 320, 207-217.

42 G. Castillo-Hernandez, M. Yasseri, B. Klobes, S. Ayachi, E. Müller and J. de Boor, J. Alloys Compd., 2020, 845, 156205.

43 Q. Chen, M. Hillert, B. Sundman, W. A. Oates, S. G. Fries and R. Schmid-Fetzer, J. Electron. Mater., 1998, 27, 961-971.

44 M. C. Peters, J. W. Doak, J. E. Saal, G. B. Olson and P. W. Voorhees, J. Electron. Mater., 2019, 48, 1031-1043.

45 U. R. Kattner, CALPHAD XXXII 2003 Conference Proceedings, 2004, pp. 241-273. 